\title{
Article
}

\section{Initial development of the Psychopathic Processing and Personality Assessment (PAPA) across populations}

Lewis, Michael, Ireland, Jane Louise, Abbott, Janice and Ireland, Carol Ann

Available at http://clok.uclan.ac.uk/14353/

Lewis, Michael ORCID: 0000-0001-5567-3569, Ireland, Jane Louise ORCID: 0000-0002-5117-5930, Abbott, Janice ORCID: 0000-0001-9851-1236 and Ireland, Carol Ann ORCID: 0000-0001-7310-2903 (2017) Initial development of the Psychopathic Processing and Personality Assessment (PAPA) across populations. International Journal of Law and Psychiatry, 54 . pp. 118-132. ISSN 0160-2527

It is advisable to refer to the publisher's version if you intend to cite from the work. http://dx.doi.org/10.1016/j.ijlp.2017.06.006

For more information about UCLan's research in this area go to

http://www.uclan.ac.uk/researchgroups/ and search for <name of research Group>.

For information about Research generally at UCLan please go to http://www.uclan.ac.uk/research/

All outputs in CLoK are protected by Intellectual Property Rights law, including Copyright law. Copyright, IPR and Moral Rights for the works on this site are retained by the individual authors and/or other copyright owners. Terms and conditions for use of this material are defined in the policies page. 
Running title: DEVELOPING A SELF-REPORT MEASURE FOR PSYCHOPATHY

Initial development of the Psychopathic Processing and Personality Assessment (PAPA) across populations

Michael Lewis, Jane L. Ireland ${ }^{1}$, Janice Abbott, Carol A. Ireland.

School of Psychology, University of Central Lancashire and Ashworth Research Centre, Mersey Care NHS Trust, UK

${ }^{1}$ Corresponding author 


\begin{abstract}
Three studies describe development of the Psychopathic Processing and Personality Assessment (PAPA). Study one outlines a literature review and Expert Delphi $(\mathrm{n}=32)$ to develop the initial PAPA. Study two validates the PAPA with 431 participants (121 male prisoners and 310 university students: 154 men, 156 women), also using the Levenson Self Report Psychopathy scale and a measure of cognitive schema and affect. Study three refined the PAPA, employing it with 50 male students and 40 male forensic psychiatric patients using clinical (interview) assessments of psychopathy: the Psychopathy Checklist - Screening Version and the Affect, Cognitive and Lifestyle assessment. The PAPA comprised four factors; dissocial tendencies; emotional detachment; disregard for others; and lack of sensitivity to emotion. It positively correlated with existing psychopathy measures. Variations across PAPA subscales were noted across samples when associated with clinical measures of psychopathy. Support for the validity of the PAPA was indicated across samples. Directions for research and application are outlined.
\end{abstract}

KEY WORDS: Psychopathy; Anti-social behaviour; Measure development; PAPA. 
Initial development of the Psychopathic Processing and Personality Assessment (PAPA)

Clinical psychopathy has been characterised by an array of different behaviours (Millon, Simonsen \& Birkett-Smith, 2003), with considerable debate regarding the components underpinning the construct. The definition outlined by Cleckley (1982) is generally accepted as the most comprehensive outline of the composition of psychopathy, namely:

"Superficial charm and good 'intelligence'; absence of delusions or other signs of irrational thinking; absence of 'nervousness' or psychoneurotic manifestations; unreliability; untruthfulness and insincerity; lack of remorse and shame; inadequately motivated antisocial behaviour; poor judgement and failure to learn by experience; pathologic egocentricity and incapacity for love; general poverty in major affective reactions; specific loss of insight; unresponsiveness in general interpersonal relations; fantastic and uninviting behaviour with drink and sometimes without; suicide rarely carried out; sex life impersonal, trivial, and poorly integrated; and a failure to follow any life plan” (p. 204).

Cleckley believed the maladaptive features of psychopathy were caused by abnormal personality development, highlighting a role for deficits in cognitive and affective processing. His definition informed development of subsequent assessments for psychopathy (e.g. Psychopathy Checklist and its variations; PCL-R, Hare, 1991, 2003; PCL-SV, Hart, Cox \& Hare, 1995). There has been criticism, however, that most common assessments of psychopathy (e.g. PCL) have over-focused on 'criminal' personality (Cooke \& Michie, 2001; Kreis et al, 2012) and not the original conceptualisation of 'abnormal' psychopathy. Assessments have also been criticised for failing to account fully for cognition and affect (e.g. Blackburn, 2007a; Dawel, 
O'Kearney, McKone \& Palermo, 2012; Flor, 2007; Ireland et al, in press, Schaich Borg \& Sinnott-Armstrong, 2013; Steuerwald \& Kosson, 2000; Wilks-Riley \& Ireland, 2012).

Arguably this is a consequence of measures not fully capturing psychological theory that outlines a specific role for cognition and affect in personality and dispositional difficulties. Examples include Beck's (1987) Theory of Emotional Disorders, Huesmann's (1998) theory of Social Information Processing, the Dysfunctional Fear Hypothesis (Lykken, 1957) and the Violence Inhibition Mechanism model (VIM; Blair, 1995). The first two recognise that biases in cognition influence information processing, giving rise to attributions of causality inconsistent with the situation. Such attributions promote abnormal affective experiences (Beck, 1987). The Dysfunctional Fear Hypothesis is more specific to psychopathy, stating how those with psychopathy have deficient emotional reactivity and therefore experience less arousal to fear (Lykken, 1957), with VIM arguing that such impairments stem from early socialisation and difficulties associated with perspective-taking (Blair, 1995).

There has certainly been considerable interest in the development of measures for psychopathy, which captures theory and attends to a number of samples. Focus has, nevertheless, remained on forensic samples (Hare, 2001, 2003; Harris \& Rice, 2006), which arguably has maintained the focus on 'criminal' personality (Cleckley, 1976, 1982). A number of psychopathy measures are available, all of which offer some degree of variation on the concept. These include self-report measures (e.g. Levenson Self-Report Psychopathy Scale: LSRP: Levenson, Kiehl \& Fitzpatrick, 1995; Self-Report Psychopathy Scale: SRP, Hare, 1985; Psychopathic Personality Inventory: PPI, Lilienfeld \& Andrews, 1996; Elemental Psychopathy Assessment: EPA, Lynam et al, 2011; and Triarchic Psychopathy Measure: TPM, Patrick, Fowles \& Krueger, 2010), observational approaches (e.g. Interpersonal Measure of 
Psychopathy: IPM, Kosson, Steuerwald, Forth \& Kirkhart, 1997; Psychopathy Q-Sort Prototype, Reise \& Oliver, 1994), interviews assessing dynamic change and incorporating staff ratings (Comprehensive Assessment of Psychopathic Personality: CAPP, Cooke, Hart, Logan \& Michie, 2004) and the more utilised clinical assessments of psychopathy incorporating interview, observation and collateral information (e.g. PCL-R, Hare, 1991, 2003; PCL-SV, Hart et al, 1995; Affect, Cognitive and Lifestyle assessment: ACL, Ireland \& Ireland, 2012).

Of these assessments only the CAPP and ACL provide detailed exploration of both affect and cognition, with no self-report measures capturing this sufficiently. This is an important omission since it is argued that an arrogant and deceitful interpersonal style, deficient affective experience, and impulsive and irresponsible behavioural style are equally required for a diagnosis of psychopathy (Cooke \& Michie, 2001). Later versions of the PCL have, for example, aimed to capture the components of psychopathy in more detail. The PCL-R has now focused on a four-factor model being applied that consists of Interpersonal, Affective, Lifestyle and Antisocial components (Hare, 2003). The absence of dedicated cognitive elements remains notable, however. The PCL-R is also a clinical assessment of psychopathy that is both time consuming and intensive to complete. Thus for many purposes (i.e. for research and for assessing psychopathy in non-institutionalised samples) the PCL-R may not always be appropriate (Copestake, Gray \& Snowden, 2011).

Given this, there have been several attempts to develop self-report measures of psychopathy to act as an alternative to the PCL-R and its derivatives. Self-report measures arguably allow for the detection of different response styles and yield useful information relating to the absence of affective traits (Lilienfeld \& Fowler, 2006). Although they can be disadvantaged over clinical measures when assessing for psychopathy owing to participant 
deception and lack of insight, these are considered false premises by which to discount their utility (Lilienfeld \& Fowler (2006). Self-report measures can provide an indication of how psychopathic individuals view themselves and the world and thus should not be too quickly discounted. Indeed, a meta-analysis examining self-reported psychopathic traits and response styles (Ray et al, 2013) concluded that individuals with psychopathy are often willing to admit to many undesirable traits and behaviours.

Early self-report psychopathy measures (e.g. the Minnesota Multiphasic Personality Inventory: Psychopathic Deviate, MMPI PD: McKinley \& Hathaway, 1944; Millon Clinical Multi-Axial Clinical Inventory-II, MCMI-II: Millon, 1987]) were criticised, as they were not specifically designed to assess psychopathy and focused on criminal deviance or antisocial behaviour (Lilienfeld \& Fowler, 2006). As noted earlier, there have been developments in the creation of self-report measures designed to directly assess the construct. It is not possible to review the contribution of all these measures within the scope of current paper but brief attention will be afforded to the most commonly applied measure (LSRP) and shared criticisms across the other measures.

The LSRP was developed to assess psychopathy in non-institutionalised samples, which paralleled the two-factor model outlined by the PCL-R (Levenson et al, 1995; Lynam, Whiteside \& Jones, 1999), with the benefit of including antisocial behaviour. This is considered relevant and required in assessing psychopathy in community/student samples (Williams, Paulhus \& Hare, 2007). The LSRP has been found to map onto the three factor components of psychopathy provided by Cooke \& Michie (2001: arrogant and deceitful interpersonal style; deficient affective experience; impulsive and irresponsible behavioural style). It also correlates well with 
the PCL-R (e.g. Brinkley, Schmitt, Smith \& Newman, 2001; Brinkley, Diamond, Magaletta \& Heigel, 2008; Sellbom, 2011).

It further captures primary and secondary psychopathy, with primary psychopaths considered callous, manipulative, selfish and untruthful, whilst secondary psychopaths are thought neurotic and engaging in antisocial behaviour driven by strong emotional impulses. Nevertheless, the LSRP fails to include items that explicitly examine a range of affect (Lynam et $a l, 1999)$ and has arguably over focused on behaviour (e.g. antisocial) for which it shares a criticism with the PCL measures. This is perhaps unsurprising to note when considered that the LSRP had a basis in the description of psychopathy offered by Hare $(1991,2003)$.

Other self-report measures, such as the Self-Report Psychopathy Scale (SRP I and II, Hart, 1985; Hare, Harpur \& Hemphill, 1989), although having strengths such as good psychometric properties (e.g. Mahmut, Menictas, Stevenson \& Homewood, 2011) have nevertheless also been criticised for representing a simple replication of the PCL measures (Lilienfeld \& Andrews, 1996) and with that sharing its criticisms. Even those measures developed with more consideration of the traits originally proposed by Cleckley (e.g. the Psychopathic Personality Inventory, PPI: Lilienfeld \& Andrews, 1996) still tend to support the two-factor structure of the PCL (Benning et al, 2003), despite aiming to concentrate on personality and not behavioural components. However, a failure to explicitly include the latter could also be a criticism since inclusion of criminality or 'misconduct' remains an accepted and useful component to retain with non-forensic samples.

There remains, nevertheless, a lack of consensus among self-report measures concerning what components should underpin the construct of psychopathy, with mixed attention given to cognition and affect. Some measures include detailed coverage of the latter but not of the former 
(e.g. The Triarchic Psychopathy Measure: TriPM, Patrick et al, 2009; PPI: Lilienfeld \& Andrews, 1996), with others focusing primarily on antisocial behaviour (LSRP; Levenson et al, 1995), with a seemingly shared exclusion of explicit cognition across all measures. In addition, there has been a tendency to develop clinical assessments for psychopathy primarily using forensic samples, with self-report measures developing from community/student populations. This has led to self-report measures being developed that have not accounted for population differences in initial validations of items and structure.

There is a need to explore the creation of a self-report measure of psychopathy whose use is not restricted to forensic samples and which attends to the more discrete elements of psychopathy and not a simple replication of the PCL group of measures. There is also inconsistency in concept expression across self-report measures. Development of a self-report measure that promotes a unified understanding of psychopathy not just focused on behaviour but including affect and cognition would consequently prove valuable.

The current study attempts to achieve this by combining a literature review and Expert Delphi to create an initial consensus of topic areas. These are then developed into items to comprise a self-report measure, the Psychopathic Processing and Personality Assessment (PAPA) that is sensitive to affect, cognition and misconduct. The PAPA is then validated across samples with particular attention to its association with measures of cognition and affect, and examination of its component structure. The validation of the PAPA will consider existing measures of psychopathy, including self-report and clinical assessments. 
Study one

This comprised a review of the relevant literature that informed an Expert Delphi focused on development of the Psychopathic Processing and Personality Assessment (PAPA).

Literature review

A systematic literature review was conducted on the area of psychopathy, accessed through the following online databases; Academic Search Complete; Medline; PsycINFO; and PsycARTICLES. Search terms 'psychopathy' and 'psychopathic personality' were used and abstracts $(n=277)$ belonging to peer-reviewed articles published over a ten-year period (i.e. 2001 to 2011) examined. Forty-eight articles deemed to address the construct and/or its measurement informed the areas for the Expert Delphi, with 229 articles excluded as they did not directly study the construct of psychopathy or its measurement. Table 1 lists the 48 articles used.

$<$ Table 1 here>

Thematic analysis was employed where themes were identified and explored that were focused on content that described the concept of psychopathy and the factors important to capture in its measurement. These themes were developed via familiarization with the literature, initial coding of papers, initial examination of themes relevant to the research questions, and the definition and naming of themes. The focus was on identifying themes that made meaningful 
contributions to the research aims (Guest, 2012; Braun \& Clarke, 2006). This was completed by the first author with the second author reviewing and confirming the proposed themes.

This resulted in identification of seven themes: Defining the construct; Interpersonal features; Behavioural characteristics; Cognition; Affect; Developmental factors; and associated health factors (e.g. link to mental illness). Fifty-eight topic areas were generated to capture these themes and are indicated in Table 2.

$<$ Table 2 here $>$

Expert Delphi

A Delphi is an interactive technique that allows the refinement of opinion over a number of rounds, with the ultimate aim to reach agreement (Skjutar, Christensson \& Millersdorf, 2009; Vosmer, Hackett \& Callanan, 2009). Responses are collated at the end of each Delphi round and fed back to participants, providing them with an opportunity to alter their previous opinion in light of the group response. It also allows each participant to provide further commentary as rounds progress. In accordance with Vosmer et al. (2009) a final consensus level of $80 \%$ was accepted.

\section{Participants}

The Expert Delphi panel was populated using a purposive sampling technique where participants were approached based on their knowledge and experience. They were identified to 
take part based on the literature review conducted. Forensic practitioners were also approached via HM Prison Service. Two hundred experts overall were approached. There was a 16 percent response rate for round one where 32 experts took part (23 from the UK, seven from North America, one from Canada, and one from Australia). Fifty-six percent of experts reported clinical experience in psychopathy assessment. Thirteen percent had published at least one-peer reviewed paper on the topic, and $31 \%$ had done both. In round two, two experts withdrew and in round three, three further experts withdrew.

\section{Method}

There were three rounds; all administered online using Survey Monkey. In round one, experts had to rate the extent to which they felt each of the 58 areas generated from the literature review best described psychopathy and should be included in a new measure. Experts were also given opportunity to suggest anything they felt was missing. An example item from round one was "Psychopathy is underpinned by an interpersonal component (selfish, callousness, and remorseless use of others)" to which experts had to rate inclusion on a Likert scale from strongly disagree (1) to strongly agree (5). The same scale was applied to all areas. Experts were given one month to complete this round.

In rounds two and three experts were asked to comment on any additional areas and to reconfirm their views based on the group opinion regarding whether or not an item should be included in the self-report measure. In both rounds experts were informed as to which areas had already reached $80 \%$ consensus and which had not, and which new areas had been proposed. The average percentage agreement and disagreement for all previous areas were provided. For 
any new proposed areas experts were asked to rate inclusion on a Likert scale as for round one. For previously included areas they had to indicate 'yes' or 'no' regarding whether or not it should be discarded. Experts were given three weeks to complete each round.

Results

Round one: Data from round one used average percentage agreement and disagreement for each item. Of the 58 areas included, 16 reached a consensus of $\geq 80 \%$ with experts indicating they agreed/strongly agreed that these areas were important and should be included in round two (i.e. areas 1, 4 to 12, 22, 23, 26, 29 and 40: see Table 2). An examination of the areas indicated that experts were replicating the PCL-R items exclusively, with further areas generated detailing behavioural characteristics, cognition, affect, developmental factors and associated health factors, all lacking expert agreement.

A thematic analysis conducted on additional comments and suggestions made by the experts demonstrated 12 themes (\% experts suggesting): Negative personality characteristics (21.9\%); Relationships with others (18.8\%); Fear and anxiety (18.8\%); Aggression (15.6\%); Poor parenting (13\%); Reasoning ability and decision making (13\%); Emotional processing (9.4\%); Substances and risk-taking behaviour (9.4\%); Schemas (9.4\%); Experience of emotion (9.4\%); Stability of the construct (6.3\%); and Gene/environment interaction (6.3\%). These were then collapsed into five super-ordinate themes; Defining the construct; Behavioural characteristics; Cognition; Affect; and Developmental factors. Inter-rater reliability of these themes was considered with another rater producing overall agreement of 74\% (Cohen's Kappa $=.26, p<.05)$. The themes generated an additional 38 areas. 
Round two: The original 58 areas were further presented as part of this round, with the additional 38 areas. Of these 96 areas, one item reached the consensus to be discarded ('psychopaths are associated with a large family size, e.g. three or more children'), 30 areas reached an agreement of $\geq 80 \%$, with the remaining 65 areas failing to meet the cut off. Overall, however, one-third of the areas were close to achieving a consensus, with 39 of the total areas reaching an average percentage agreement or disagreement that fell between 60 percent and 79 percent.

Experts made additional suggestions in this round beyond the PCL definition, suggesting three additional areas, covering the topics of 'fear and anxiety' (13.3\% proposed one item); and 'views relating to themselves and others' (6.7\% proposed two areas). Inter-rater reliability was calculated on these proposed themes with $100 \%$ agreement obtained. Round three then proceeded by presenting areas via two sections; 'Agreement' and 'No agreement' to ensure a final check and opinion consensus. Also presented were these two additional themes.

Round three: The final round consisted of 99 areas; 96 areas from round two and the three new areas proposed. For inclusion in the final self-report measure each item had to reach an average agreement for inclusion of $\geq 80 \%$. Forty-three areas reached agreement for inclusion, with these indicated in Table 3. This final round demonstrated how experts generally viewed psychopathy as underpinned by interpersonal features and behavioural characteristics. In terms of cognitive and affective processing, experts agreed that those with psychopathy have biased judgments of causality, possess maladaptive cognitive schemas, displayed low fearfulness, have an impaired emotional learning and a different internal experience of emotion, and are less 
influenced by emotion. Experts viewed psychopathic individuals as experiencing developmental problems, specifically poor parental/caregiver modeling.

$<$ Table 3 here>

Two additional areas that did not reach the required consensus cut-off, namely impulsivity (74.1\% wanted inclusion) and psychopathy is best viewed as a personality disorder (77.7\% wanted inclusion) were also retained as the academic literature highlights them to be particularly important components (e.g. Blackburn, 2007b; Ray, Poythress, Weir \& Rickelm, 2009). Their final inclusion/exclusion was determined in the following study. The initial Psychopathic Processing and Personality Assessment (PAPA-I) therefore proceeded with 45 agreed areas.

Transformation of themes into self-report areas

These 45 areas were simplified and transformed into the first person in accordance with recommendations by Bowling (2009) and Rattray and Jones (2007) to produce self-report items. For example, the Expert Delphi area 'Psychopaths manipulate others for their own needs' was presented as 'I will use people to get what I want'. Expert Delphi areas containing more than one component were split to aid comprehension. For example, the area 'Glibness/superficial charm' was separated into 'I am able to talk myself out of situations by not answering questions directly' and 'I am described as a charmer by those that know me'. The new self-report measure contained 54 items in total, capturing all 45 areas, and mixed to ensure their inclusion of negatively and positively worded items (Rattray \& Jones, 2007). These items are presented in Figure 1. 
Readability of the new measure was determined using the Flesch-Kincaid Test, which indicated participants were required to reach a reading age of 10 to 11 to complete the measure. The timeframe used for the new self-report measure was 'in general' to ensure that it did not capture transient presentations but trait presentation. Participants were instructed to rate the extent to which each item best described them using a five-point Likert scale ranging from very unlike me (1) to very like me (5). The reliability and validity of the PAPA-I was examined in the ensuing study.

\section{Discussion}

Results indicated that experts agreed psychopathy could be understood through interpersonal factors, behavioural characteristics, deficits in cognition and affect, and developmental factors. They appeared influenced by the PCL-R definition of psychopathy, which was consistent with Skeem and Cooke (2010) who recognised that the theoretical construct and the assessment of psychopathy have become somewhat synonymous. It would not be unreasonable to expect that experts rated familiar items more favourably, with this accounting for the high level of agreement on the PCL-R items. However, the study did incorporate a literature review, acknowledging the role of affect with psychopathy (Cleckley, 1982; Dawel et al. 2012) even though this has been neglected in some assessments of psychopathy. Affect, as a component, appeared accepted by experts. Experts also accepted cognition as important to the construct of psychopathy (e.g. Blackburn, 2007a; Wilks-Riley \& Ireland, 2012; Schaich Borg \& Sinnott-Armstrong, 2013) despite its primary absence from measures of psychopathy.

Nevertheless, experts rated affect as more associated than cognition, with interpersonal and 
behavioural features of psychopathy the most highly rated. Indeed, cognitive processing was poorly captured in experts' understanding of the disorder.

Expert understanding of psychopathic cognition and affect did overlap with a number of psychological theories, including Beck's (1987) theory of Emotional Disorders and Huesmann's (1998) theory of Social Information Processing, which recognise a role for cognition and (with Social Information Processing) biased attributions of causality linked to inaccurate affective experiences. The Dysfunctional Fear Hypothesis (Lykenn, 1957) and VIM (Blair, 1995) also appear to have been captured in experts' understanding although they attended less to the early developmental experiences proposed by VIM and how these relate to cognition and affect. Clearly, however, the sample of experts used in the Delphi was varied in background, with a combination of academics, academic-practitioners and practitioners working with this client group utilised. Although it was important to capture both academics and practitioners considering the focus of the research was to develop a self-report measure that had utility both clinically and academically, the homogeneity of the sample regarding their background still requires acknowledgement (Hsu \& Sandford, 2007) as a potential limitation that could have influenced the results. The number of experts used were also small, over half of which were Forensic Psychologists. Such individuals will have administered the PCL-R as part of their roles, which may have biased their responses towards the PCL-R assessment content. A larger and more diverse expert pool would have assisted although it is important to note that the current study was not just influenced by expert reviews but also by a systematic literature review that captured a range of themes relevant to psychopathy. Indeed, whilst experts gravitated towards the PCL-R definition, the inclusion of items associated with cognition and affect based on the literature review allowed for their understanding of psychopathy, and indeed the new self-report 
measure, to be aligned with theory. The structure and content of this measure will be considered in the ensuing study.

Study two

Participants

Four hundred adult male prisoners were given questionnaire packs, with 121 returning these, resulting in a response rate of 30\%. Regarding students, 705 were given packs, with 301 (154 men and 156 women) returning these, producing a response rate of $44 \%$.

All prisoners were recruited from a Category B (medium to high risk) prison in the UK. Thirty-two percent reported their current offence to be for violence, $17 \%$ drug-related, $19 \%$ acquisitive and $22 \%$ as 'other' (e.g. driving offences, property damage). Ten percent did not disclose their main offence. The average age was 31.6 years $(S D=9.5)$. Students were sampled from a UK university. The average was 23.2 years $(S D=6.6: 23$ years men, $S D=6.1$; 23 years women, $S D=7.2$ ).

Method

\section{Measures}

The study employed the following measures:

Psychopathic Processing and Personality Assessment - (PAPA-I): Consisting of 54 items (see Figure 1) rated on a five-point Likert scale ranging from very unlike me (1) to very like me 
(5). Prior to administering the PAPA-I it was piloted with students $(n=20)$ to assess its readability and layout. No difficulties were noted.

The Levenson Self-Report Psychopathy Scale (LSRP; Levenson et al, 1995): A 26 item self-report measure to assess psychopathic traits within community and forensic samples. The LSRP broadly corresponds to both factors of the PCL-R defined clinical psychopathy, i.e. factor one (F1; primary psychopathy), was assessed through 16 items such as, 'looking out for myself is my top priority' and 'I often admire a really clever scam'. Factor two (F2; secondary psychopathy) examined through ten items such as, 'I don't plan anything very far in advance'. Items were rated on a four-point Likert scale ranging from strongly disagree (1) to strongly agree (4).

Schemata: Positive and Negative, and Affect assessment - version two (SPANA-II; Wilks-

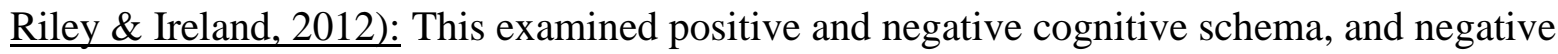
affect associated with psychopathy using 65 items. Negative cognitive schema was assessed through items such as 'I am isolated' and 'I hate myself', whilst positive cognitive schema was associated with items such as 'I get on well with others' and 'I am a caring person'. Items such as, 'I am not in touch with my emotions' and 'I am fairly cut off from my feelings' were used to address negative affect. Participants had to rate the items on a five-point Likert scale ranging from strongly disagree (1) to strongly agree (5).

\section{Procedure}

All participants received a study coversheet. This included information on the purpose of the research, the procedure used, consent and withdrawal process and confidentiality. Ethical approval was obtained from the University of Central Lancashire and the National Research 
Ethics Service (NRES). Students were recruited from recreational areas on-campus, including canteens and common rooms. They were given details on how to return their completed questionnaires to the psychology office. Prisoners completed the measure pack on their own in their cells. Completed packs were collected direct from prisoners.

Data was analysed using SPSS. Data screening was conducted prior to analysis. Little's MCAR test indicated that missing data was random for the prisoner sample $\left(\chi^{2}=4032.5\right.$, df $=$ 4500, $\mathrm{p}>.05)$, but not the student sample $\left(\chi^{2}=3735.8, \mathrm{df}=3304, \mathrm{p}<.001\right)$. Missing data was consequently replaced for the forensic sample using Expectation Maximisation. Mahalanobis Distance $(\mathrm{p}<.001)$ indicated 34 cases (22 prisoners and 12 students) as multivariate outliers. These were thus removed from the data set. No univariate outliers were identified. Three hundred and ninety seven cases (99 prisoners and 298 students) were thus utilised.

Statistical Analysis

Mean scores and internal reliability across each measure are presented in Table 4. Higher scores are indicative of higher levels of the respective concept.

<Table 4 here>

A MANOVA indicated an overall multivariate effect $(\mathrm{F}=11.11$, df 5, 363, $p<.0001)$, with a number of significant univariate effects. Prisoners had higher psychopathy scores than students on both the PAPA-I $(\mathrm{F}(1,367)=37.9, p<.001)$ and $\operatorname{LSRP}(\mathrm{F}(1,367)=23.2, p<.001)$. Prisoners also had higher levels of negative schemas $(\mathrm{F}(1,367)=38.9, p<.001)$ and negative 
affect $(\mathrm{F}(1,367)=6.24, p<.013)$. There was no significant difference with positive schemas ( $\mathrm{F}$ $(1,367)=1.21 \mathrm{~ns})$.

Structure of the PAPA-I and differences across resulting subscales

A Principle Components Analysis using Oblimin rotation was employed to examine the structure of the PAPA-I. This was completed across the sample to account for sample size and item number $(\mathrm{n}=383,54$ items). A scree plot indicated a four-factor solution. Factor loadings were restricted to .50 for inclusion. Fifteen items did not load onto any component. Four items were removed from factor two and three from factor four due to negatively correlating with the remainder of the scale. No further items negatively correlated with any of the remaining factor scales. Table 5 presents the four-factor solution with means and reliabilities.

$<$ Table 5 here>

The four factors captured dissocial tendencies (nine items); emotional detachment (five items); disregard for others (10 items); and a lack of sensitivity to emotion (eight items). A MANOVA indicated an overall multivariate effect $(\mathrm{F}=27.0, \mathrm{df} 4,385, p<.0001)$, with two significant univariate effects for factor one (dissocial) and factor four (lack of sensitivity to emotion). Prisoners presented with higher scores on both factors (factor one: $\mathrm{F}(1,388)=81.8$, $p<.001$; factor four: $(1,388)=24.1, p<.001)$, than students. 


\section{Associations between PAPA-I and LSRP}

A positive correlation was found between overall PAPA-I and LSRP scores $(r=.80, \mathrm{n}=$ 393, $p<.001$ ). The LSRP positively correlated with all components of the PAPA-I (factor one: dissocial: $r=.64, \mathrm{n}=392, p<.001$; factor two: emotional detachment: $r=.52, \mathrm{n}=392, p<.001$; factor three: disregard for others: $r=.68, \mathrm{n}=391, p<.001$; factor four: lack of sensitivity to emotion: $r=.60, \mathrm{n}=390, p<.001)$ samples. Across primary and secondary psychopathy scores on the LSRP, there was a positive correlation between overall PAPA-I and Primary LSRP psychopathy $(r=.70, \mathrm{n}=381, p<.001)$ and secondary LSRP psychopathy $(r=.68, \mathrm{n}=392$, $p<.001)$. These correlations held across prisoners and students when completed separately. LSRP primary psychopathy positively correlated with all components of the PAPA-I (factor one: dissocial: $r=.51, \mathrm{n}=394, p<.001$; factor two: emotional detachment: $r=.44, \mathrm{n}=$ $395, p<.001$; factor three: disregard for others: $r=.70, \mathrm{n}=392, p<.001$; factor four: lack of sensitivity to emotion: $r=.46, \mathrm{n}=392, p<.001)$. LSRP secondary psychopathy positively correlated with all components of the PAPA-I (factor one: dissocial: $r=.64, \mathrm{n}=394, p<.001$; factor 2: emotional detachment: $r=.47, \mathrm{n}=395, p<.001$; factor 3: disregard for others: $r=.43, \mathrm{n}$ $=393, p<.001$; factor 4: lack of sensitivity to emotion: $r=.63, \mathrm{n}=392, p<.001)$ samples. Again, these correlations held across prisoners and students when completed separately.

Thus as psychopathy scores on the PAPA-I increased, so did psychopathy scores on the LSRP, with this holding across factors (i.e. PAPA-I factors and LSRP factors) and samples.

Predicting psychopathy across PAPA-I and LSRP: Association with schemas and affect

To determine further the cohesion between the PAPA-I and the LSRP, their independent association with schemas and affect were examined. Two multiple regressions were completed, 
one considering the most significant predictors of total PAPA-I scores and one for total LSRP scores. In both instances entered predictors included negative affect, and positive and negative schema totals.

For the PAPA-I, the Multiple Regression was significant $(\mathrm{F}(3,370)=123.6, p<.001)$, with the predictors accounting for $50 \%$ of the variance $\left(\mathrm{R}^{2}=.50\right.$, Adjusted $\left.\mathrm{R}^{2}=.49\right)$. Negative schemas, positive schemas and negative affect scores were all positive predictors $(t=9.57$, $p<.001 ; t=2.91, p<.004 ; t=7.05, p<.001)$; as totals increased so did levels of psychopathy. When considered across samples, the results were replicated aside from Positive Schemas for students, which did not present as a significant predictor ${ }^{1}$.

For the LSRP, the Multiple Regression was significant $(\mathrm{F}(3,378)=111.6, p<.001)$, with predictors accounting for $47 \%$ of the variance $\left(\mathrm{R}^{2}=.47\right.$, Adjusted $\left.\mathrm{R}^{2}=.46\right)$. Negative schemas, positive schemas and negative affect scores were all positive predictors $(t=7.89, p<.001 ; t=$ $4.85, p<.001 ; t=6.96, p<.001)$ : as all totals increased so did levels of psychopathy. When considered across samples, the results were replicated ${ }^{2}$.

\section{Discussion}

The PAPA-I was found to perform well with regards to internal reliability, both overall and across the resulting factors. The four factors identified were best described as dissocial tendencies, emotional detachment, disregard for others, and a lack of sensitivity to emotion. Although capturing cognitive components of psychopathy, these were less clearly delineated. Indeed, cognition appeared as part of the 'disregard for others' factor, which also comprised affect. This factor was interesting in that it seemed to combine a lack of concern and an uncaring 
and objectifying view of others, with a grandiose sense of self. It suggested that the affective component of psychopathy was integrated with the more cognitive components of empathy, namely an inability to appreciate others and their experiences. An absence of empathic affect and grandiosity, which is captured within existing measures of psychopathy (e.g. Hare, 2003), but the PAPA-I factor illustrated more the specific cognitions that were likely to underpin this (e.g. that others are objects).

This suggests that although there is a role for cognition in the measurement of psychopathy that it is presenting in combination with affect and it may be difficult therefore to separate these elements. Nevertheless, it supported a role for both affect and cognition in psychopathy assessment (e.g. Cleckley, 1982; Dawel et al. 2012; Blackburn, 2007a; Wilks-Riley \& Ireland, 2012), with affect captured more significantly as a unique factor. Interestingly, affect did not just focus on the experiencing of affect but the absence of experience, and thus a deficit in the experiencing of emotion (Blair, 1995). This is particularly consistent with models such as the Dysfunctional Fear Hypothesis (Lykken, 1957).

Dissocial behaviour also still presented as a core component. This provided evidence for its continued utility as a recognised distinct element in psychopathy (Williams et al, 2007). Indeed, in the current study, 'criminal history and lifestyle' appeared covered across two PAPA factors; dissocial behaviour and disregard for others. The PAPA-II also associated with the LSRP, as an existing self-report measure of psychopathy. This held across PAPA-II factors and LSRP components of primary and secondary psychopathy. Indeed, the dissocial component of the PAPA-II correlated most highly with secondary psychopathy, which is most closely aligned to the criminal history and lifestyle component of psychopathy referenced in other assessments (e.g. PCL-R; Hare, 2003). This provided evidence for concurrent validity, which was further 
supported by equality in presentation across the PAPA-II and LSRP regarding their associations with cognitive schema and negative affect.

Overall, the patterns regarding the latter were the same, with increased scores on both the PAPA-II and LSRP predicted by increased cognitive schema (positive and negative) and negative affect. The PAPA-II was therefore associated with increased negative cognitive schema and negative affect. This held across samples with the exception of student samples and positive schemas where such schemas did not present as a predictor of PAPA-II scores. Despite this, there was broad consistency between measures across schemas and affect, with this further indicating a role for these components in the prediction of psychopathy (Cleckley, 1982; Blackburn, 2007a; Wilks-Riley \& Ireland, 2012).

The current study is not without its limitations. Response rates, although not unusual for this type of methodology, were not high and due to the anonymous nature of the study it was not possible to provide any information on those who chose not to return questionnaires. Associating the PAPA-I with further measures of psychopathy would assist with determining its validity in more detail. Only a single measure of psychopathy was applied here as the associating measure. The measure of negative affect on the SPANA-II is also limited and a wider assessment of affect could determine its validity with this particular component. Nevertheless, the current study is focused on the initial development of a self-report measure and provides evidence that cognition and affect are central to psychopathy defined by both expert consensus and pre-existing definitions. Widening examination of the PAPA-I in relation to its association with broader, more clinical, measures of psychopathy is the focus of the next study. 
Study three

\section{Participants}

Of the 111 patients approached 41 did not consent (37\%), 20 were transferred during the recruitment period or on trial leave (18\%), eight were deemed unwell by their Responsible Clinician (7\%), and one withdrew (1\%). This resulted in 41 patients consenting and engaging (37\%), with one later being removed due to failing to complete one of the psychopathy measures (the ACL). The final sample of patients was thus 40. Regarding students, 52 expressed interest in engaging, with 50 of these subsequently consenting, resulting in a response rate of $96 \%$. For patients, the average age was 40.1 years $(S D=9.0)$, and for students the average age was 22.5 $(S D=4.43)$.

Method

Measures

Affect, Cognitive and Lifestyle assessment (Ireland \& Ireland, 2012) ${ }^{3}$ : is a measure of psychopathic functioning that covers affect, cognition, lifestyle [behaviour] and interpersonal style. It is a structured interview, which also comprises a range of ability and observational components. For forensic samples it also incorporated an assessment of collateral information, with such information clearly unavailable for student samples. Thirty-three areas of functioning were rated on an overall scale of 0 (no problems) to 3 (extreme problems). Increased scores on this assessment are indicative of increased levels of psychopathy. 
Psychopathic Processing and Personality Assessment - version two (PAPA-2): Based on the results of study two the PAPA-II was reduced to 29 items for final analysis. Removed items included those that did not load onto any of the four factors indicated or those that negatively correlated. An additional four items were removed as they did not fit fully with the theme of the factors, two from dissocial tendencies ('I have a problem using alcohol' and 'I am described as a charmer by those that know me'), one from emotional detachment ('I have clear goals for my long-term future') and one from lack of sensitivity to emotion ('I regularly view others as irritating'). Two remaining items had their wording slightly altered to aid clarity; 'I can often find myself viewing others as nothing more than objects' became 'I can often find myself viewing others as nothing more than 'objects' or things to be used'; 'I use illegal drugs more than most people I know' became 'I use illegal drugs, or those that are not prescribed to me, more than most people I know'. Analysis proceeded with the remaining 29 items. A five-point Likert scale ranging from very unlike me (1) to very like me (5) was utilised.

Psychopathic Checklist - Screening Version (PCL-SV: Hart, Cox \& Hare, 1995). This is a 12-item checklist for assessing psychopathy that has been validated for use with community and forensic samples. It gathers information using an interview and, if available, collateral information. For the current study collateral information review was restricted to forensic patients. The PCL-SV comprised two factors; factor one: interpersonal style and factor two: criminal history and lifestyle. 
Procedure

Responsible Clinicians provided consent for patients to be involved. Students were asked directly to engage, with poster and adverts used to generate the sample. All interviews lasted approximately 1 to 1.5 hours and were conducted individually in a private room. All participants were paid a small honorarium to engage. Two patients failed to complete two affective items and had their scores replaced with the group mean. The data was analysed using SPSS.

Statistical analysis

Correlations were considered separately across the samples owing to the ACL and PCLSV incorporating collateral information as well as interview for the forensic sample and not for the student sample. This also ensured that means could not be compared on the ACL and PCLSV for forensic and student samples. Table 6 presents the correlations across samples between the ACL, PCL-SV and PAPA-2, including across factors. The reliability and means for each measure is also indicated.

$<$ Insert Table 6 here>

Positive correlations were indicated between the PAPA-II total, PCL-SV and ACL totals (all $r$ 's 2.34). This held across samples although correlations were higher for student than forensic samples. 
Across PAPA-II Factors, emotional detachment (factor two) failed to correlate with the other measures of psychopathy for students, and failed to correlate with the criminal history and lifestyle (factor two) component of the PCL-SV for the forensic sample. Factor three of the PAPA-II (disregard for others) failed to correlate with the criminal history and lifestyle component of the PCL-SV for students and, for forensic patients, failed to correlate with the PCL-SV or any of its components. Finally, for forensic patients, factor one of the PAPA-II (dissocial tendencies) failed to correlate with the interpersonal style (factor one) component of the PCL-SV, with the PAPA-II factor lack of sensitivity to emotion (factor four) failing to correlate with the criminal history and lifestyle component of the PCL-SV, or the ACL score, although there was a trend for the latter.

\section{Discussion}

Overall, the PAPA-II positively associated with the clinical psychopathy assessments. This provided further evidence for concurrent validity. Correlations between the PAPA-II and the PCL and ACL were higher for students than forensic psychiatric patients. There were also some variations in presentation of the PAPA-II factors across samples; factor two of the PAPA-II (emotional detachment) failed to significantly correlate with the measures for the student sample, or with factor two (criminal history and lifestyle) of the PCL-SV for the forensic sample. In addition, factor three (disregard for others) of the PAPA-II did not correlate with the psychopathy measures for the forensic sample. However, this factor presents as a combination of both affect and cognitive elements and there is criticism that the PCL does not capture these elements sufficiently (e.g. Cooke \& Michie, 2001; Kreis et al, 2012). This could explain the lack 
of association with this specific measure, although more broadly (and including the ACL) it could suggest that this factor may not be associating with existing interview-based measures of psychopathy.

This does suggest differences regarding how the subscales of the PAPA-II consistently perform across samples regarding how they associate with existing clinical measures of psychopathy. Nevertheless, the overall PAPA-II score appeared the most stable of the correlating factors. Indeed, the differences across PAPA-II subscales suggested that it might be the subscales and not the total that are performing differently across samples. This could indicate that the PAPA-II is sensitive to population differences. Furthermore, the absence of a correlation between factor one PAPA-II (dissocial tendencies) and the interpersonal style component of the PCL-SV for the forensic sample provides some evidence for discriminate validity as these are supposed to be separate factors (Hare, 2003). The same can be indicated for the lack of a correlation between factor four of the PAPA-II (lack of sensitivity to emotion) and this PCL-SV factor (criminal history and lifestyle) since lack of sensitivity to emotion is considered associated more with the interpersonal style component of the PCL-SV for which there was a correlation. Indeed this was the highest correlation of the set.

Nevertheless, the current study is limited by the small sample size and focus on men. This is a product largely of the specialised nature of the forensic psychiatric sample and the small participant numbers by both this and the intense assessment required, which can markedly limit the participant pool available. Indeed, the response rate of patients was not particularly high but complicated by transfers, trial leaves and not being well enough to engage; this is simply a challenging sample to acquire for a study of this nature. Despite this, the study provides 
preliminary evidence of the PAPA-II correlating with existing clinical measures of psychopathy and in doing so providing further evidence for concurrent validity.

General discussion

The series of studies presented here argue for the importance of cognition and affect as integral elements of psychopathy assessments and incorporating these into a self-report measure of psychopathy (PAPA). The PAPA was initially based on a literature review and expert Delphi, which assisted in producing a comprehensive measure that demonstrated evidence for both concurrent validity with self-report and clinical assessments of psychopathy, as well as sensitivity to affect and cognition.

In addition, it appears to have utility across forensic and student samples and was able to distinguish between them; study two, for example, indicated how prisoners scored higher on the PAPA-I than students both overall and particularly in relation to the dissocial tendencies factor. It would be expected not only for prisoners to score more highly but particularly so on the dissocial tendencies component, providing evidence that the PAPA-I was able to discriminate between samples. Indeed, similarities of findings between the prisoner and student sample in relation to PAPA-I factors two (emotional detachment) and three (disregard for others) could be indicative more of developmental (i.e. age) differences than psychopathy, with students representing a younger sample. Nevertheless, the fact differences were noted, with this extended to factor components, suggests specific manifestations and aetiologies of psychopathy that are unique to different populations. This is inconsistent with more recent conceptualisations of psychopathy as a homogenous entity (e.g. Harpur, Hare \& Hakstian, 1989; Hare, 1991; Cooke \& 
Michie, 2001). The current study suggests more heterogeneity across samples with regards to this concept. Indeed, although current assessments of psychopathy provide differing norms for populations, the possibility of weighting items differently or incorporating population specific components has yet to be considered.

The four factors indicated by the PAPA were of particular interest. The structure indicated appeared to support Cooke \& Michie's (2001) argument for specific components to be included for any diagnosis of psychopathy. The components put forward by Cooke \& Michie appeared consistent with the PAPA factor structure, for example arrogant and deceitful interpersonal style was captured by the PAPA factor 'disregard for others'; deficient affective experience by the PAPA factors emotional detachment and lack of sensitivity to emotion, and impulsive and irresponsible behaviour by the PAPA factor dissocial behaviour. Indeed, the PAPA structure bore similarities to both the components suggested by Cooke \& Michie and also those by Hare (2003) in the four-factor model of the PCL-R that comprised components of interpersonal, affective, lifestyle and antisocial functioning. The PAPA, however, appears to be including more focus on affect and cognition within its noted factor structure.

There are limitations to these studies, most of which have been captured earlier. Nevertheless, it will be important to note the need for future research to confirm the PAPA's structure using a larger and more diverse sample to allow for confirmatory factor analysis of the measure to be determined. In addition, the current series of studies focused on the content, structure and concurrent validity of the measure and did not extend this to test-retest reliability. This will be important area to address and will capture the stability of the PAPA alongside other measures of psychopathy and personality such as the five factor models of personality (e.g. Costa \& McCrae, 1992). Future research should be expected to build on this area further by assessing 
the PAPA alongside other concepts of potential relevance such as deception and externalizing symptoms/behaviours of psychopathy (e.g. behavioural symptoms such as drug use, alcohol use etc.), to broaden its application and potential validity.

\section{References}

Bagley, A. D., Abramowitz, C. S., Kosson, D. S. (2009). Vocal affect recognition and psychopathy: Converging findings across traditional and cluster analytic approaches to assessing the construct. Journal of Abnormal Psychology, 118, 388-398.

Beck, A. T. (1987). Cognitive models of depression. Journal of Cognitive Psychotherapy, 1, 537.

Benning, S. D., Patrick, C. J., Hicks, B. M., Blonigen, D. M., Krueger, R. F. (2003). Factor structure of the Psychopathic Personality Inventory: Validity and implications for clinical assessment. Psychological Assessment, 15, 340-350.

Berardino, S. D., Meloy, J. R., Sherman, M., Jacobs, D. (2005). Validation of the Psychopathic Personality Inventory on a female sample of inmates. Behavioural Sciences and the Law, $23,819-836$.

Blackburn, R. (2007a). Personality disorder and antisocial deviance: Comments on the debate on the structure of the Psychopathy Checklist-Revised. Journal of Personality Disorders, 21, 142-159.

Blackburn, R. (2007b). Personality disorder and psychopathy: Conceptual and empirical integration. Psychology, Crime, and Law, 13, 7-18.

Blackburn, R., Logan, C., Donnelly, J. P., Renwick, S. D. (2008). Identifying psychopathic subtypes: Combining an empirical personality classification of offenders with the Psychopathy Checklist-Revised. Journal of Personality Disorders, 22, 604-622.

Blagov, P. S., Patrick, C. J., Lilienfeld, S. O., Powers, A. D., Phifer, J. E., Venables, N., Hudak, M., Herres, D. J., Lieb, K., Garvin Leigh, S. C., Cooper, G. (2011). Personality constellations in incarcerated psychopathic men. Personality Disorders: Theory, Research and Treatment, 2, 293-315. 
Blair, R. J. R. (1995). A cognitive developmental approach to morality: Investigating the psychopath. Cognition, 57, 1-29.

Bowling, A. (2009). Research Methods in Health: Investigating Health and Health Services $\left(3^{\text {rd }}\right.$ ed.). Maidenhead: Open University Press.

Braun, V., Clarke, V. (2006). Using thematic analysis in psychology. Qualitative Research in Psychology, 3, 77 - 101.

Brinkley, C. A., Diamond, P. M., Magaletta, P. R., Heigel, C. P. (2008). Cross-validation of Levenson's psychopathy scale in a sample of federal female inmates. Assessment, 15, 464-482.

Brinkley, C. A., Schmitt, W. A., Smith, S. S., Newman, J. P. (2001). Construct validation of a self-report psychopathy scale: does Levenson's self-report psychopathy scale measure the same constructs as Hare's psychopathy checklist-revised? Personality and Individual Differences, 31, 1021-1038.

Claes, L., Vertommen, S., Soenens, B., Eyskens, A., Rens, E., Vertommen, H. (2009). Validation of the Psychopathic Personality Inventory among psychiatric patients: Sociodemographic, cognitive, and personality correlates. Journal of Personality Disorders, 23, 477-493.

Cleckley, H. (1976). The Mask of Sanity (5 ${ }^{\text {th }}$ ed.). St. Louis, Missouri: The C. V. Mosby Company.

Cleckley, H. (1982). The Mask of Sanity (rev ed.). St. Louis, Missouri: The C. V. Mosby Company.

Coid, J., Min, Y. (2008). The distribution of psychopathy among a household population: categorical or dimensional? Social Psychiatry and Psychiatric Epidemiology, 43, 773781.

Cooke, D. J., Hart, S. D., Logan, C., Michie, C. (2004). Comprehensive Assessment of Psychopathic Personality - Institutional Rating Scale (CAPP-IRS). Unpublished Manual.

Cooke, D. J., Michie, C. (1997). An item response theory analysis of the Hare psychopathy checklist - revised. Psychological Assessment, 9, 3-14.

Cooke, D. J., Michie, C. (2001). Refining the construct of psychopathy: Towards a hierarchical model. Psychological Assessment, 13, 171-188. 
Copestake, S., Gray, N. S., Snowden, R. J. (2011). A comparison of a self-report measure of psychopathy with the psychopathy checklist-revised in a UK sample of offenders. The Journal of Forensic Psychiatry and Psychology, 22, 169-182.

Costa, P. T., McCrae, R. R. (1992). Normal Personality Assessment in Clinical Practice: The NEO Personality Inventory. Psychological Assessment, 4, 5-13.

Dawel, A., O'Kearney, R., McKone, E., Palermo, R. (2012). Not just fear and sadness: Metaanalytic evidence of pervasive emotion recognition deficits for facial and vocal expressions in psychopathy. Neuroscience and Biobehavioral Reviews, 36, 2288-2304.

Decuyper, M., De Pauw, S., De Fruyt, F., De Bolle, M., De Clercq, B. (2009). A meta-analysis of psychopathy, antisocial pd and FFM associations. European Journal of Personality, 23, 531-565.

Derefinko, K. J., \& Lynam, D. R. (2007). Using the FFM to conceptualize psychopathy: A test using a drug abusing sample. Journal Of Personality Disorders, 21, 638-656.

Edens, J. F., McDermott, B. E. (2010). Examining the construct validity of the Psychopathic Personality Inventory-Revised: Preferential correlates of fearless dominance and selfcentered impulsivity. Psychological Assessment, 22, 32-42.

Flor, H. (2007). Cognitive correlates. In A. R. Felthous., \& H. Sass (Eds.), The International Handbook on Psychopathic Disorder and the Law, volume one (pp. 103-116). Chichester: John Wiley and Sons.

Glass, S. J., Newman, J. P. (2006). Recognition of facial affect in psychopathic offenders. Journal of Abnormal Psychology, 115, 815-820.

Guest, G. (2012). Applied Thematic Analysis. Thousand Oaks, California

Guy, L. S., Edens, J. F., Anthony, C., Douglas, K. S. (2005). Does psychopathy predict institutional misconduct among adults? A meta-analytic investigation. Journal of Consulting and Clinical Psychology, 73, 1056-1064.

Habel, U., Kühn, E., Salloum, J. B., Devos, H., Schneider, F. (2002). Emotional processing in psychopathic personality. Aggressive Behavior, 28, 394-400.

Hansen, A., Johnsen, B., Thornton, D., Waage, L., Thayer, J. F. (2007). Facets of psychopathy, heart rate variability and cognitive function. Journal of Personality Disorders, 21, 568582. 
Hare, R. D. (1985). A comparison of procedures for the assessment of psychopathy. Journal of Consulting and Clinical Psychology, 53, 7-16.

Hare, R. D. (1991). The Hare Psychopathy Checklist-Revised. Toronto, Ontario: Multi-Health Systems.

Hare, R. D. (2003). The Hare Psychopathy Checklist-Revised, $2^{\text {nd }}$ edition. Toronto, Ontario: Multi-Health Systems.

Hare, R. D., Harpur, T. J., Hemphill, J. F. (1989). Scoring pamphlet for the Self-Report Psychopathy Scale: SRP-II. Unpublished document, Simon Fraser University, Vancouver, Canada.

Hare, R. D., Neumann, C. S. (2009). Psychopathy: Assessment and forensic implications. The Canadian Journal of Psychiatry, 54, 791-802.

Hare, R. D., Neumann, C. S. (2010). The role of antisociality in the psychopathy construct: Comment on Skeem and Cooke (2010). Psychological Assessment, 22, 446-454.

Harpur, T. J., Hare, R. D., Hakstian, A. R. (1989). Two-factor conceptualization of psychopathy: Construct validity and assessment implications. Psychological Assessment, 1, 6-17.

Harris, G. T., Rice, M. E. (2006). Treatment of psychopathy: A review of empirical findings. In C. J. Patrick (Ed.), Handbook of psychopathy (pp. 555-572). London: The Guildford Press.

Hart, S., Cox, D., Hare, R. D. (1995). Manual for the Psychopathy Checklist: Screening Version (PCL:SV). Toronto: Multi-Health Systems.

Hicks, B. M., Vaidyanathan, U., Patrick, C. J. (2010). Validating female psychopathy subtypes: Differences in personality, antisocial and violent behavior, substance abuse, trauma, and mental health. Personality Disorders: Theory, Research and Treatment, 1, 38-57.

Huesmann, L. R (1998) The role of social information processing and cognitive schema in the acquisition and maintenance of habitual aggressive behaviour, In R. G. Geen and E. Donnerstein (Ed.), Human Aggression: Theories, Research, and Implications for Social Policy (73-109). London: Academic Press Ltd.

Hsu, C.C., Sandford, B.A. (2007).The Delphi Technique: Making Sense of Consensus. Practical Assessment, Research \& Evaluation, 12, (10), 1 - 8.

Ireland, J. L., Ireland, C. A. (2012). Affect, Cognitive, and Lifestyle Assessment (ACL). Unpublished Manual, University of Central Lancashire, Preston, UK. 
Ireland, J. L., Ireland, C. A., Lewis, M., Miller, C., Keeley. (in press). Affective, Cognitive and Lifestyle (ACL): Initial development of an implicit and explicit approach to assess psychopathy. International Journal of Law and Psychiatry.

Kennealy, P. J., Skeem, J. L., Walters, G. D., Camp, J. (2010). Do core interpersonal and affective traits of PCL-R psychopathy interact with antisocial behavior and disinhibition to predict violence? Psychological Assessment, 22, 569-580.

Kosson, D. S., Stuerwald, B. L., Forth, A. E., Kirkhart, K. J. (1997). A new method for assessing the interpersonal behaviour of psychopaths: Preliminary validation studies. Psychological Assessment, 9, 89-101.

Kreis, M. K. F., Cooke, D. J. (2011). Capturing the psychopathic female: A prototypicality analysis of the Comprehensive Assessment of Psychopathic Personality (CAPP) across gender. Behavioural Sciences and the Law, 29, 634-648.

Kreis, M. K. F., Cooke, D. J., Michie, C., Hoff, H. A., Logan, C. (2012). The Comprehensive Assessment of Psychopathic Personality (CAPP): Current validation using prototypical analysis. Journal of Personality Disorders, 26, 402-413.

Lee, Z., Salekin, R. T. (2010). Psychopathy in a noninstitutional sample: Differences in primary and secondary subtypes. Personality Disorders: Theory, Research and Treatment, 1, 153169.

Levenson, M. R., Kiehl, K. A., Fitzpatrick, C. M. (1995). Assessing psychopathic attributes in a noninstitutionalized population. Journal of Personality and Social Psychology, 68, 151158.

Lilienfeld, S. O., Andrews, B. P. (1996). Development and preliminary validation of a self-report measure of psychopathic personality traits in noncriminal populations. Journal of Personality Assessment, 66, 488-524.

Lilienfeld, S. O., \& Fowler, K. A. (2006). The self-report assessment of psychopathy. In C. J. Patrick (Ed.), Handbook of psychopathy (pp. 107-132). London: The Guildford Press.

Lindberg, N., Laajasalo, T., Holi, M., Putkonen, H., Weizmann-Henelius, G., HäkkänenNyholm, H. (2009). Psychopathic traits and offender characteristics - a nationwide consecutive sample of homicidal male adolescents. BMC Psychiatry, 9, 1-11.

Long, L., Titone, D. A. (2007). Psychopathy and verbal emotion processing in non-incarcerated males. Cognition and Emotion, 21, 119-145. 
Lykken, D. T. (1957). A study of anxiety in the sociopathic personality. Journal of Abnormal and Social Psychology, 55, 6-10.

Lynam, D. R., Gaughan, E. T., Miller, J. D., Miller, D. J., Mullins-Sweatt, S., Widiger, T. A. (2011). Assessing the basic traits associated with psychopathy: Developmental and validation of the elemental psychopathy assessment. Psychological Assessment, 23, 108124.

Lynam, D. R., Whiteside, S., Jones, S. (1999). Self-reported psychopathy: A validation study. Journal of Personality Assessment, 73, 110-132.

Mahmut, M. K., Menictas, C., Stevenson, R. J., Homewood, J. (2011). Validating the factor structure of the Self-Report Psychopathy Scale in a community sample. Psychological Assessment, 23, 670-678.

Marcus, D. K., John, S. L., Edens, J. F. (2004). A taxometric analysis of psychopathic personality. Journal of Abnormal Psychology, 113, 626-635.

Maron, B. E., Sellbom, M. (2011). An examination of gender-moderated test bias on the Levenson Self-Report Psychopathy Scale. Journal of Personality Assessment, 93, 235243.

Mayer, A. R., Kosson, D. S., Bedrick, E. J. (2006). Neuropsychological implications of selective attentional functioning in psychopathic offenders. Neuropsychology, 20, 614-624.

McKinley, J. C., Hathaway, S. R. (1944). The Minnesota Multiphasic Personality Inventory: V. Hysteria, hypomania and psychopathic deviate. Journal of Applied Psychology, 28, 153174.

Millon, T. (1987). Millon Clinical Multiaxial Inventory (MCMI-II) Manual. Minneapolis: National Computer Systems.

Millon, T., Simonsen, E., Birket-Smith, M. (2003). Historical conceptions of psychopathy in the United States and Europe. In T. Millon., E. Simonsen., M. Birket-Smith., \& R. D. Davis (Eds.), Psychopathy: Antisocial, criminal, and violent behavior (pp. 3-31). New York: Guildford Press.

Miranda, R. R., MacKillop, J., Meyerson, L. A., Justus, A., Lovallo, W. R. (2009). Influence of antisocial and psychopathic traits on decision-making biases in alcoholics. Alcoholism: Clinical and Experimental Research, 33, 817-825. 
Neumann, C. S., Hare, R. D. (2008). Psychopathic traits in a large community sample: Links to violence, alcohol use, and intelligence. Journal of Consulting and Clinical Psychology, 76, 893-899.

Neumann, C. S., Hare, R. D., Newman, J. P. (2007). The super-ordinate nature of the Psychopathy Checklist-Revised. Journal of Personality Disorders, 21, 102-117.

Neumann, C. S., Malterer, M. B., Newman, J. P. (2008). Factor structure of the Psychopathic Personality Inventory (PPI): Findings from a large incarcerated sample. Psychological Assessment, 20, 169-174.

Ogloff, J. R. P. (2006). Psychopathy/antisocial personality disorder conundrum. Australian and New Zealand Journal of Psychiatry, 40, 519-528.

Patrick, C. J., Edens, J. F., Poythress, N. G., Lilienfeld, S. O., Benning, S. D. (2006). Construct validity of the Psychopathic Personality Inventory two-factor model with offenders. Psychological Assessment, 18, 204-208.

Patrick, C. J., Fowles, D. C., Krueger, R. F. (2009). Triarchic conceptualization of psychopathy: Developmental origins of disinhibition, boldness, and meanness. Development and Psychopathology, 21, 913-938.

Pereira, N., Huband, N., Duggan, C. (2008). Psychopathy and personality. An investigation of the relationship between the NEO-Five Factor Inventory (NEO-FFI) and the Psychopathy Checklist-Revised (PCL-R) in a hospitalized sample of male offenders with personality disorder. Criminal Behaviour and Mental Health, 18, 216-223.

Rattray, J., Jones, M. C. (2007). Essential elements of questionnaire design and development. Journal of Clinical Nursing, 16, 234-243.

Ray, J. V., Hall, J., Rivera-Hudson, N., Poythress, N. G., Lilienfeld, S. O., Morano, M. (2013). The relation between self-reported psychopathic traits and distorted response styles: A meta-analytic review. Personality Disorders: Theory, Research, and Treatment, 4, 1-14.

Ray, J. V., Poythress, N. G., Weir, J. M., Rickelm, A. (2009). Relationships between psychopathy and impulsivity in the domain of self-reported personality features. Personality and Individual Differences, 46, 83-87.

Reise, S. P., Oliver, C. J. (1994). Development of a California Q-set indicator of primary psychopathy. Journal of Personality Assessment, 62, 130-144. 
Ruiz, M. A., Pincus, A. L., Schinka, J. A. (2008). Externalizing pathology and the Five-Factor Model: A meta-analysis of personality traits associated with antisocial personality disorder, substance use disorder, and their co-occurrence. Journal of Personality Disorders, 22, 365-388.

Sadeh, N., Verona, E. (2008). Psychopathic personality traits associated with abnormal selective attention and impaired cognitive control. Neuropsychology, 22, 669-680.

Sadeh, N., Verona, E., Javdani, S., Olson, L. (2009). Examining psychopathic tendencies in adolescence from the perspective of personality theory. Aggressive Behavior, 35, 399407.

Schaich Borg, J., Sinnott-Armstrong, W. P. (2013). Do psychopaths make moral judgments? In K. A. Kiehl, \& W. P. Sinnott-Armstrong (Eds.), Handbook on Psychopathy and Law (pp. 107-130). Oxford: Oxford University Press.

Seibert, L., Miller, J. D., Few, L. R., Zeichner, A., Lynam, D. R. (2011). An examination of the structure of self-report psychopathy measures and their relations with general traits and externalizing behaviors. Personality Disorders: Theory, Research and Treatment, 2, 193208.

Skeem, J. L., Cooke, D. J. (2010). Is criminal behavior a central component of psychopathy? Conceptual directions for resolving the debate. Psychological Assessment, 22, 433-445.

Skeem, J. L., Mulvey, E. P., Grisso, T. (2003). Applicability of traditional and revised models of psychopathy to the Psychopathy Checklist: Screening Version. Psychological Assessment, 15, 41-55.

Skjutar, A., Christensson, K., Müllersdorf, M. (2009). Exploring indicators for pain rehabilitation: A Delphi study using a multidisciplinary expert panel. Musculoskeletal Care, 7, 227-242.

Smith, S., Edens, J. F., Vaughn, M. G. (2011). Assessing the external correlates of alternative factor models of the Psychopathic Personality Inventory-Short Form across three samples. Journal of Personality Assessment, 93, 244-256.

Verona, E., Patrick, C. J., Joiner, T. E. (2001). Psychopathy, antisocial personality, and suicide risk. Journal of Abnormal Psychology, 110, 462. 
Verschuere, B., Crombez, G., De Clercq, A., Koster, E. W. (2005). Psychopathic traits and autonomic responding to concealed information in a prison sample. Psychophysiology, 42, 239-245.

Vitacco, M. J., Lishner, D. A., Neumann, C. S. (2012). Assessment. In H. Häkkänen-Nyholm, \& J. Nyholm (Eds.), Psychopathy and law: A practitioner's guide (pp. 19-32). Chichester, West Sussex: John Wiley and Sons.

Vosmer, S., Hackett, S., Callanan, M. (2009). "Normal" and "inappropriate" childhood sexual behaviours: Findings from a Delphi study of professionals in the United Kingdom. Journal of Sexual Aggression, 15, 275-288.

Walsh, Z., Allen, L. C., Kosson, D. S. (2007). Beyond social deviance: Substance use disorders and the dimensions of psychopathy. Journal of Personality Disorders, 21, 273-288.

Walters, G. D., Brinkley, C. A., Magaletta, P. R., Diamond, P. M. (2008). Taxometric analysis of the Levenson Self-Report Psychopathy Scale. Journal of Personality Assessment, 90, 491-498.

Warren, G. C., Clarbour, J. (2009). Relationship between psychopathy and indirect aggression use in a noncriminal population. Aggressive Behavior, 35, 408-421.

Wilks-Riley, F., Ireland, J. L. (2012). Cognition and psychopathy: Identifying negative and positive schemas in general and forensic samples. The Journal of Forensic Psychiatry and Psychology, 23, 466-484.

Williams, K. M., Paulhus, D. L., Hare, R. D. (2007). Capturing the four-factor structure of psychopathy in college students via self-report. Journal of Personality Assessment, 88, 205-219.

Wogan, M., Mackenzie, M. (2007). An inmate classification system based on PCL: SV factor scores in a sample of prison inmates. Journal of Offender Rehabilitation, 44, 25-42.

Wright, E. M. (2009). The measurement of psychopathy: Dimensional and taxometric approaches. International Journal of Offender Therapy and Comparative Criminology, $53,464-481$. 


\section{Footnotes}

${ }^{1}$ For prisoners the regression was significant $(\mathrm{F}(3,98)=27.6, p<.001)$, with the predictors accounting for $47 \%$ of the variance $\left(\mathrm{R}^{2}=.47\right.$, Adjusted $\left.\mathrm{R}^{2}=.45\right)$. Negative schemas, positive schemas and negative affect were all positive predictors $(\mathrm{t}=3.54, p<.001 ; \mathrm{t}=2.50, \mathrm{p}<.04 ; \mathrm{t}=$ $3.73, p<.001)$. For students the regression was significant $(\mathrm{F}(3,271)=81.9, p<.001)$, with the predictors accounting for $48 \%$ of the variance $\left(\mathrm{R}^{2}=.48\right.$, Adjusted $\left.\mathrm{R}^{2}=.47\right)$. Negative schemas and negative affect were all positive predictors $(\mathrm{t}=7.71, p<.001 ; \mathrm{t}=6.12, p<.001)$. As totals increased so did levels of psychopathy.

${ }^{2}$ For prisoners, the multiple regression was significant $(\mathrm{F}(3,98)=23.3, p<.001)$, with the predictors accounting for $42 \%$ of the variance $\left(\mathrm{R}^{2}=.42\right.$, Adjusted $\left.\mathrm{R}^{2}=.41\right)$. Negative schemas, positive schemas and negative affect scores were all positive predictors $(\mathrm{t}=3.64, p<.001 ; \mathrm{t}=$ $2.32, p<.02 ; \mathrm{t}=3.07, p<.003)$. For students, the multiple regression was significant $(\mathrm{F}(3,279)=$ $78.3, p<.001)$, with the predictors accounting for $46 \%$ of the variance $\left(\mathrm{R}^{2}=.46\right.$, Adjusted $\mathrm{R}^{2}=$ .45). Negative schemas, positive schemas and negative affect scores were all positive predictors $(\mathrm{t}=5.44, p<.001 ; \mathrm{t}=4.50, p<.001 ; \mathrm{t}=6.52, p<.001)$. As all totals increased so did levels of psychopathy.

${ }^{3}$ The ACL is a new measure of psychopathic functioning. The results of study three concerning the ACL and PCL-SV data form part of a wider validation study (see Ireland, Ireland, Lewis, Jones \& Keeley, in press). The ACL data and its association with the PCL-SV is analysed in more detail in this further study. The focus in the current paper is on the PAPA development and not the ACL. 
Figure 1.

Original 54 items used for PAPA-1

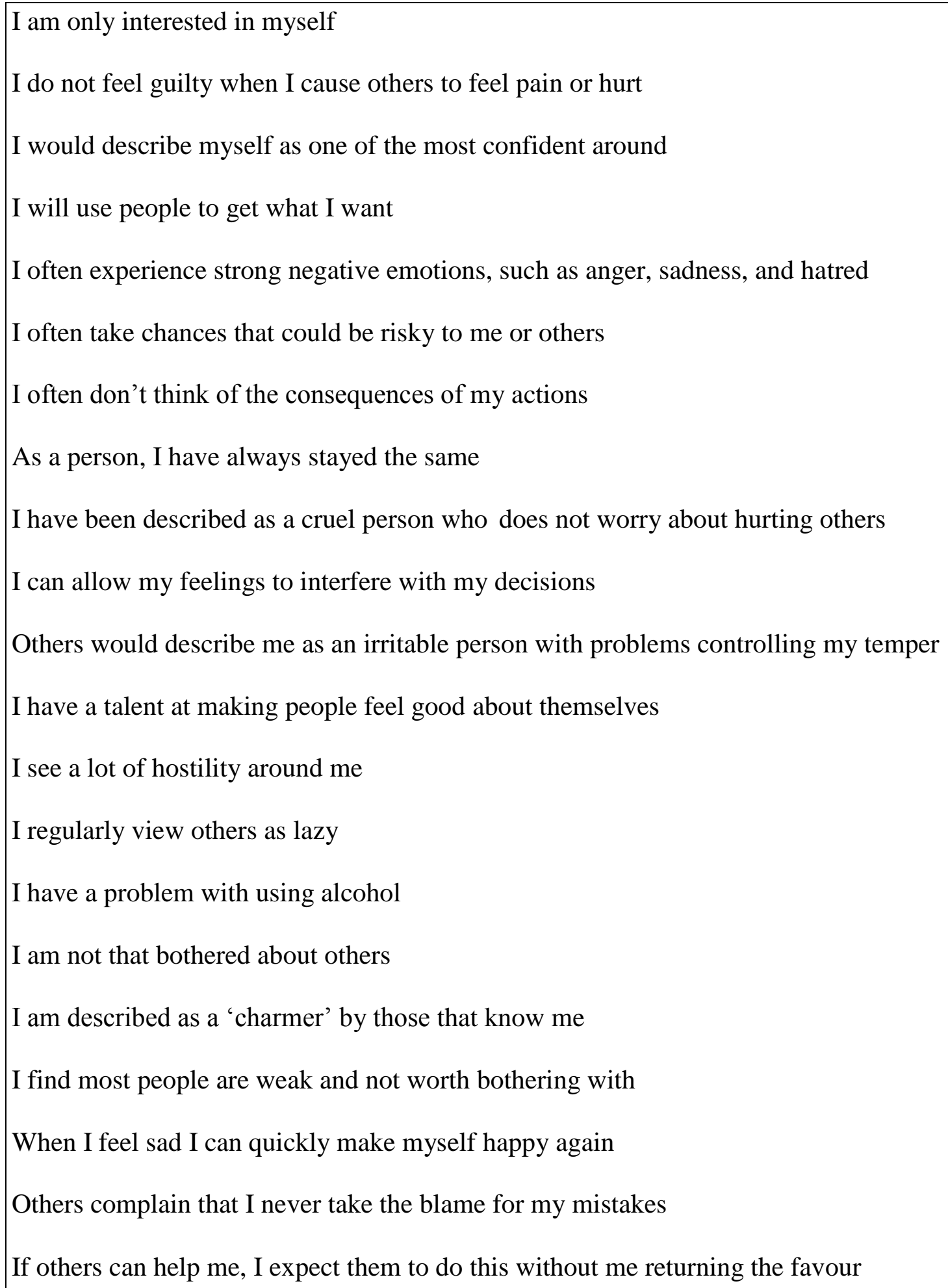


I find it impossible to resist temptation

I often get into trouble more than others

I tend to keep in touch with those close to me

I find it difficult to comfort others when they are upset

I would describe myself as someone who is often 'fearless' when faced with a threat

I am a creative person who can think of more than one way of dealing with problems

The world is a threatening place, you have to 'watch your back'

I often feel in touch with other people's feelings

I am able to talk myself out of situations by not answering questions directly

If I am caught out on a lie I can quickly think of a way out

I often experience strong positive emotion, such as happiness and joy

I am often bored

I regularly view others as irritating

I see no problem in living off the State/Government

I enjoy doing things that are exciting or new

I am able to commit a wide number of behaviours that, if caught, would get me into trouble

I can often find myself viewing others as nothing more than 'objects'

I am an aggressive person in a number of situations

I very rarely experience fear

I tend to think of one solution to a problem and stick to it

I use illegal drugs more than most people I know

I find it difficult to give emotional and personal support to others

If I do something wrong I will feel bad about it 
I often find myself thinking that I am more important than others

I have been described as a 'fraudster' or a 'con artist' by those who know me

I always accept responsibility for what I do

I don't see why others can't take care of me

I can be unpredictable

I often find people behave aggressively or in a hostile manner towards me

Others would describe me as a very intense person who has difficulty getting on with others

I find it easy to form strong emotional relationships with others

As a child I often got into trouble more than others

I have clear goals for my long-term future 


\section{Table 1}

Articles used to generate the areas for Expert Delphi round one $(n=48)$.

\begin{tabular}{|c|c|c|}
\hline Author(s) & Year & Title \\
\hline $\begin{array}{l}\text { Bagley, Abramowitz \& } \\
\text { Kosson }\end{array}$ & 2009 & $\begin{array}{l}\text { Vocal affect recognition and psychopathy: Converging findings across traditional and cluster } \\
\text { analytic approaches to assessing the construct. }\end{array}$ \\
\hline $\begin{array}{l}\text { Benning, Patrick, Hicks, } \\
\text { Blonigen \& Krueger }\end{array}$ & 2003 & $\begin{array}{l}\text { Factor structure of the Psychopathic Personality Inventory: Validity and implications for clinical } \\
\text { assessment. }\end{array}$ \\
\hline $\begin{array}{l}\text { Blackburn, Logan, } \\
\text { Donnelly \& Renwick }\end{array}$ & 2008 & $\begin{array}{l}\text { Identifying psychopathic subtypes: Combining an empirical personality classification of offenders } \\
\text { with The Psychopathy Checklist-Revised. }\end{array}$ \\
\hline Blagov et al. & 2011 & Personality constellations in incarcerated psychopathic men. \\
\hline Claes et al. & 2009 & $\begin{array}{l}\text { Validation of the Psychopathic Personality Inventory among psychiatric inpatients: Socio- } \\
\text { demographic, cognitive and personality correlates. }\end{array}$ \\
\hline Copestake, Gray \& & 2011 & A comparison of a self-report measure of psychopathy with the psychopathy checklist-revised in a \\
\hline Snowden & & UK sample of offenders. \\
\hline Decuyper et al. & 2009 & A meta-analysis of psychopathy, antisocial PD and FFM associations. \\
\hline Derefinko \& Lynam & 2007 & Using the FFM to conceptualize psychopathy: A test using a drug abusing sample. \\
\hline Edens \& McDermott & 2010 & $\begin{array}{l}\text { Examining the construct validity of the Psychopathic Personality Inventory-Revised: Preferential } \\
\text { correlates of fearless dominance and self-centered impulsivity. }\end{array}$ \\
\hline
\end{tabular}




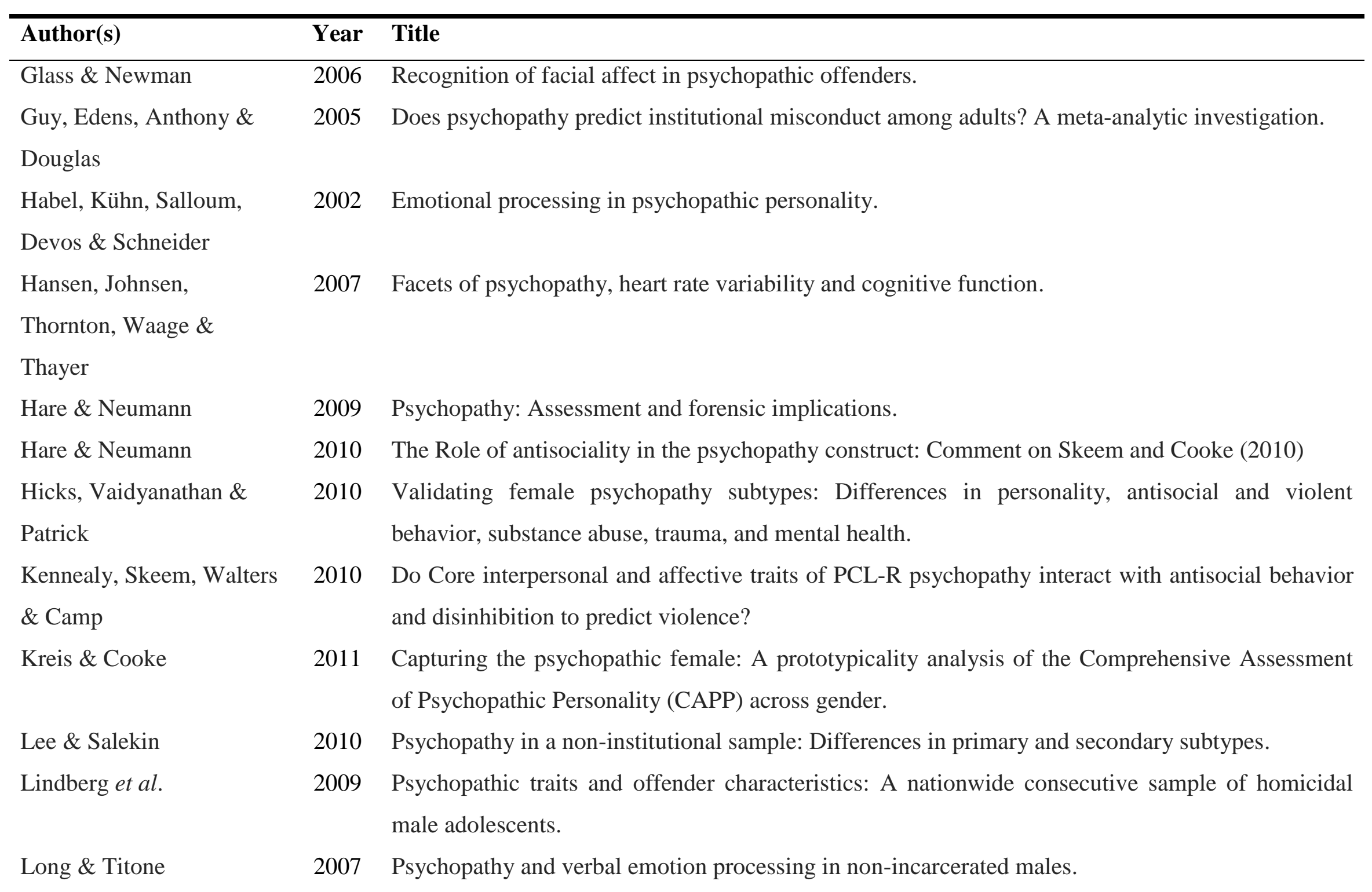




\begin{tabular}{|c|c|c|}
\hline Author(s) & Year & Title \\
\hline Lynam et al. & $2011 b$ & $\begin{array}{l}\text { Assessing the basic traits associated with psychopathy: Development and validation of the } \\
\text { elemental psychopathy assessment. }\end{array}$ \\
\hline Marcus, John \& Edens & 2004 & A taxometric analysis of psychopathic personality. \\
\hline Marion \& Sellbom & 2011 & An examination of gender-moderated test bias on the Levenson Self-Report Psychopathy Scale. \\
\hline Mayer, Kosson \& Bedrick & 2006 & Neuropsychological implications of selective attentional functioning in psychopathic offenders. \\
\hline $\begin{array}{l}\text { Miranda, MacKillop, } \\
\text { Meyerson, Justus \& }\end{array}$ & 2009 & Influence of antisocial and psychopathic traits on decision-making biases in alcoholics. \\
\hline Lovallo & & \\
\hline Neumann \& Hare & 2008 & Psychopathic traits in a large community sample: Links to violence, alcohol use, and intelligence. \\
\hline $\begin{array}{l}\text { Neumann, Hare \& } \\
\text { Newman }\end{array}$ & 2007 & The super-ordinate nature of the Psychopathy Checklist-Revised. \\
\hline $\begin{array}{l}\text { Neumann, Malterer \& } \\
\text { Newman }\end{array}$ & 2008 & $\begin{array}{l}\text { Factor structure of the Psychopathic Personality Inventory (PPI): Findings from a large } \\
\text { incarcerated sample. }\end{array}$ \\
\hline Ogloff & 2006 & Psychopathy/antisocial personality disorder conundrum. \\
\hline $\begin{array}{l}\text { Patrick, Edens, Poythress, } \\
\text { Lilienfeld \& Benning }\end{array}$ & 2006 & Construct validity of the Psychopathic Personality Inventory two-factor model with offenders. \\
\hline Pereira, Huband \& & 2008 & Psychopathy and personality. An investigation of the relationship between the NEO-Five Factor \\
\hline Duggan & & $\begin{array}{l}\text { Inventory (NEO-FFI) and the Psychopathy Checklist-Revised (PCL-R) in a hospitalized sample of } \\
\text { male offenders with personality disorder. }\end{array}$ \\
\hline Ruiz, Pincus \& Schinka & 2008 & $\begin{array}{l}\text { Externalizing pathology and the five-factor model: A meta-analysis of personality traits associated } \\
\text { with antisocial personality disorder, substance misuse, and their co-occurrence. }\end{array}$ \\
\hline
\end{tabular}




\begin{tabular}{|c|c|c|}
\hline Author(s) & Year & Title \\
\hline Sadeh \& Verona & 2008 & $\begin{array}{l}\text { Psychopathic personality traits associated with abnormal selective attention and impaired cognitive } \\
\text { control. }\end{array}$ \\
\hline $\begin{array}{l}\text { Sadeh, Verona, Javdani \& } \\
\text { Olson }\end{array}$ & 2009 & Examining psychopathic tendencies in adolescence from the perspective of personality theory. \\
\hline Seibert et al. & 2011 & $\begin{array}{l}\text { An examination of the structure of self-report psychopathy measures and their relations with } \\
\text { general traits and externalizing behaviours. }\end{array}$ \\
\hline Skeem, Mulvey \& Grisso & 2003 & $\begin{array}{l}\text { Applicability of traditional and revised models of psychopathy to the Psychopathy Checklist: } \\
\text { Screening Version. }\end{array}$ \\
\hline Smith, Edens \& Vaughn, & 2011 & $\begin{array}{l}\text { Assessing the external correlates of alternative factor models of the Psychopathic Personality } \\
\text { Inventory-Short Form across three samples. }\end{array}$ \\
\hline Verona, Patrick \& Joiner & 2001 & Psychopathy, antisocial personality and suicide risk. \\
\hline $\begin{array}{l}\text { Verschuere, Crombez, De } \\
\text { Clercq \& Koster }\end{array}$ & 2005 & Psychopathic traits and autonomic responding to concealed information in a prison sample. \\
\hline Viding & 2004 & Annotation: Understanding the development of psychopathy. \\
\hline Walsh, Allen \&Kosson & 2007 & Beyond social deviance: Substance use disorders and the dimensions of psychopathy. \\
\hline $\begin{array}{l}\text { Walters, Brinkley, } \\
\text { Magaletta \& Diamond }\end{array}$ & 2008 & Taxometric analysis of the Levenson Self-Report Psychopathy Scale. \\
\hline Warren \& Clarbour & 2009 & Relationship between psychopathy and indirect aggression use in a noncriminal population. \\
\hline Wilson et al. & 2011 & $\begin{array}{l}\text { An examination of the validity of the Elemental Psychopathy Assessment: Relations with other } \\
\text { psychopathy measures, aggression and externalizing behaviours. }\end{array}$ \\
\hline Wogan \& Mackenzie & 2007 & An inmate classification system based on PCL: SV factor scores in a sample of prison inmates. \\
\hline
\end{tabular}


Table 2

Areas included in Expert Delphi round one.

\section{Areas}

\section{Defining the Construct}

1. Psychopathy is underpinned by an interpersonal component (selfish, callousness, and remorseless use of others).

2. Psychopathy is underpinned by a socially deviant behavioural component (a chronically unstable and antisocial lifestyle).

3. Offending behaviour is a correlate, rather than a component of psychopathy.

Psychopathy is defined through a series of abnormal personality traits:

4. Glibness/superficial charm

5. Grandiose sense of self-worth

6. Pathological lying

7. Conning/manipulative

8. Lack of remorse or guilt

9. Shallow affect

10. Callous/lack of empathy

11. Failure to accept responsibility for actions

12. Need for stimulation/proneness to boredom

13. Parasitic lifestyle

14. Poor behavioural controls

15. Early behavioural problems

16. Lack of realistic, long-term goals

17. Impulsivity

18. Irresponsibility

19. Juvenile delinquency

20. Revocation of conditional release

21. Promiscuous sexual behaviour.

22. Psychopaths have a propensity to engage in thrill and adventure seeking behaviour.

23. Psychopathy is best viewed as a personality disorder. 


\section{Areas}

24. Psychopathy is manifested at an early age, but remains stable over the course of an individual's life.

25. Psychopathy is a dynamic construct, i.e. an individual's level of psychopathy can increase or decrease over their life.

\section{Interpersonal Features}

26. Psychopaths have difficulties in forming and maintaining personal bonds.

27. Psychopaths perceive others as 'objects' rather than people.

\section{Behavioural Characteristics}

28. Psychopaths do not respond to punishment.

29. Psychopaths are represented by high rates of recidivism.

30. Psychopaths are often criminally versatile.

31. Psychopaths are poorly integrated.

\section{Cognition}

32. Psychopaths do not attend to information that is not central to an event, i.e. they ignore peripheral information.

33. Psychopaths have biased judgments of causality.

34. Psychopaths have an organised pattern of thought that is distorted.

35. Psychopaths often interpret everyday social situations as aggressive or hostile.

36. Psychopaths have difficulties with abstract concepts.

37. Psychopaths have a lack of insight.

38. Psychopaths are able to accurately evaluate and use emotive language when explicitly directed to do so.

39. Psychopaths are unable to inhibit their responses to avoid punishment.

\section{$\underline{\text { Affect }}$}

40. Psychopaths are less influenced by emotion, e.g. emotional words, in comparison to nonpsychopaths.

41. Psychopaths are unable to recognise and understand emotion and therefore do not modify their behaviour accordingly.

42. Psychopaths are less sensitive to experiencing emotion because they are trying to avoid experiencing negative emotion. 


\section{Areas}

43. Psychopaths display low fearfulness.

\section{Developmental Factors}

44. Psychopathy results from problems in attachment that occurs during infancy.

45. Attachment problems that have occurred between a child and their caregiver(s) are unlikely to lead to psychopathy.

46. Psychopaths often experience damage to their personality during childhood.

47. Psychopaths have a harsh and rejecting childhood.

As a child, a psychopath will have been exposed to:

48. Poor parenting, such as emotional abuse

49. Physical and/or sexual abuse

50. Caregiver conflict

51. Caregiver separation

52. A large family size, e.g. three or more children.

\section{Associated Health Factors}

53. High levels of psychopathy often occur along with an Axis I disorder, i.e. mental illness.

54. Psychopaths are more likely than non-psychopaths to exaggerate Axis I (mental illness) symptoms, or malinger.

55. Psychopaths regularly use illicit substances

56. Psychopaths exhibit more alcohol and drug-dependence symptoms than non-psychopaths.

57. Psychopaths who use illicit substances are more likely to have personality challenges.

58. Psychopaths with a substance misuse problem often have a co-occurring mental illness. 
Areas reaching expert consensus on Expert Delphi Round three for inclusion (i.e. expert agreement of $80 \%$ or more).

\begin{tabular}{|c|c|c|}
\hline & & Percentage (\%) \\
\hline Areas & Theme & Agreement \\
\hline $\begin{array}{l}\text { 1. Psychopathy is underpinned by an interpersonal component (selfish, callousness, and } \\
\text { remorseless use of others). }\end{array}$ & Defining features & 100 \\
\hline 2. Conning/manipulative. & Defining features & 100 \\
\hline 3. Lack of remorse or guilt. & Defining features & 100 \\
\hline 4. Callous/lack of empathy. & Defining features & 100 \\
\hline 5. Psychopaths manipulate others for their own needs. & Interpersonal & 100 \\
\hline 6. Psychopaths think of themselves rather than others. & Cognition & 100 \\
\hline 7. Irresponsibility. & Defining features & 96.3 \\
\hline 8. Psychopaths have difficulties in forming and maintaining personal bonds. & Interpersonal & 96.3 \\
\hline 9. Shallow affect. & Defining features & 96.3 \\
\hline 10. Failure to accept responsibility for actions. & Defining features & 96.3 \\
\hline 11. Psychopaths view others instrumentally. & Interpersonal & 96.3 \\
\hline 12. Psychopaths can have both stable and dynamic features. & Defining features & 96.2 \\
\hline 13. Grandiose sense of self-worth. & Defining features & 96.2 \\
\hline $\begin{array}{l}\text { 14. Psychopaths are less influenced by emotion, e.g. emotional words, in comparison to } \\
\text { non-psychopaths. }\end{array}$ & Affect & 92.6 \\
\hline 15. Psychopaths have a propensity to engage in thrill and adventure seeking behaviour. & Defining features & 92.6 \\
\hline
\end{tabular}




\begin{tabular}{|c|c|c|}
\hline Areas & Theme & Agreement \\
\hline 16. Glibness/superficial charm. & Defining features & 92.6 \\
\hline 17. Psychopaths frequently use violence/aggression. & Behavioural & 92.6 \\
\hline 18. Psychopaths display low fearfulness. & Affect & 92.6 \\
\hline 19. Pathological lying. & Defining features & 92.5 \\
\hline 20. Poor behavioural controls. & Defining features & 88.9 \\
\hline 21. Early behavioural problems. & Defining features & 88.9 \\
\hline 22. Psychopaths perceive others as 'objects' rather than people. & Interpersonal & 88.5 \\
\hline 23. Psychopaths are often criminally versatile. & Behavioural & 85.2 \\
\hline 24. Psychopaths are cruel to others. & Defining features & 85.2 \\
\hline 25. Psychopaths are unsentimental. & Interpersonal & 85.2 \\
\hline 26. Not all psychopaths express their symptoms through criminal behaviour. & Behavioural & 85.2 \\
\hline 27. In the community, individuals with psychopathy often channel their psychopathic & Behavioural & 85.2 \\
\hline \multicolumn{3}{|l|}{ traits into an environment that supports them. } \\
\hline 28. Lack of realistic, long-term goals. & Defining features & 85.2 \\
\hline 29. Psychopaths regularly use illicit substances. & Health factors & 85.2 \\
\hline 30. Psychopaths have an impaired emotional learning. & Affect & 84.6 \\
\hline 31. Psychopaths have a different internal experience of emotion. & Affect & 84.6 \\
\hline 32. Poor parental/caregiver role modeling. & Developmental & 84.6 \\
\hline 33. Need for stimulation/proneness to boredom. & Defining features & 81.5 \\
\hline 34. Parasitic lifestyle. & Defining features & 81.5 \\
\hline
\end{tabular}




\section{Areas}

35. Psychopaths feel superior to others, i.e. they view others as weak.

36. Offending behaviour is a correlate, rather than a component of psychopathy.

37. Psychopathy is manifested at an early age, but remains stable over the course of an individual's life.

38. Relative fearlessness in the context of threat.

39. A psychopath's charm and their positive attitude can leave other feeling motivated and enthused.

40. Psychopaths have biased judgments of causality.

41. Psychopaths possess maladaptive cognitive schemas.

42. Psychopaths experience high levels of certain kinds of affect, i.e. anger and irritation.

43. Psychopaths experience high levels of certain kinds of affect, i.e. joy, sadness, and anxiety.

\section{Theme}

Interpersonal

Defining features

Defining features

Affect

Interpersonal

Cognition

Cognition

Affect

Affect
81.5

81.5

81.5

81.5

\section{5}

81.5

81.5

81.5

80.8 
Table 4

Means across PAPA-I, LSRP and SPANA-II overall and across samples.

\begin{tabular}{lcccc}
\hline Totals & Overall (n/SD) & Prisoner (n/SD) & Student (n/SD) & $\boldsymbol{\alpha}(\mathbf{n})$ \\
\hline PAPA-1 & $125.4(383 / 21.8)$ & $136.4(99 / 23.8)$ & $121.7(284 / 19.8)$ & $.88(383)$ \\
LSRP & $52.1(393 / 11.2)$ & $56.5(99 / 11.8)$ & $50.7(294 / 10.6)$ & $.88(393)$ \\
SPANA - II: & $60.3(392 / 11.4)$ & $61.3(99 / 14.3)$ & $59.9(293 / 10.3)$ & $.87 *(392)$ \\
Positive schema & & & & \\
SPANA -II: & $71.2(388 / 18.9)$ & $80.9(99 / 20.9)$ & $67.9(289 / 17.1)$ & $.94 * *(388)$ \\
Negative schema & & & & \\
SPANA - II: & $11.2(396 / 3.45)$ & $11.8(99 / 3.49)$ & $11.1(297 / 3.4)$ & $.63 * * *[396]$ \\
Negative affect & & & & \\
\hline \multicolumn{1}{c}{$*$ 29 items; $* 30$ Items; $* * 5$ items } &
\end{tabular}


Table 5

Item and factor loadings for each PAPA-I component (NB: Cronbach's alpha for each component is in parenthesis).

Item Factor loading

number Item

F1: Dissocial tendencies $(\alpha=.82$; Sum of squared loadings $=6.39$ : Overall mean 20.37, SD 7.25, $\mathrm{n}=$ 396; Prisoner mean 25.5, SD 8.14, $\mathrm{n}=$ 99; Student mean 18.6, SD 6.01, $\mathrm{n}=297$ )

$\begin{array}{lll}23 . & \text { I often get into trouble more than others }\end{array}$

6. I often take chances that could be risky to me or others 63

7. I often don't think of the consequences of my actions 62

53. As a child I often got into trouble more than others $\quad .60$

42. I use illegal drugs more than most people I know 59

37. I am able to commit a wide number of behaviours that, if caught, would $\quad .58$ get me into trouble

22. I find it impossible to resist temptation $\quad .54$

15. I have a problem with using alcohol 46

17. I am described as a 'charmer' by those that know me

F2: Emotional detachment $(\alpha=.65$; Sum of squared loadings = 3.74; Mean 10.81, SD 3.51, $n=397$;

Prisoner mean 11.1, SD 4.04, $n=$ 99; Student mean 10.7, SD 3.32, n = 298)

29. I often feel in touch with other people's feelings $\quad-.47$

47. I always accept responsibility for what I do $\quad-.47$

43. I find it difficult to give emotional and personal support to others -.45

25. I find it difficult to comfort others when they are upset -.43

54. I have clear goals for my long-term future $\quad-.40$

F3: Disregard for others $(\alpha=.82$; Sum of squared loadings $=6.85$; Mean 19.6, SD 6.3; $n=394$;

Prisoner mean 20.1, SD 6.9, $\mathrm{n}=$ 99; Student mean 19.5, SD 6.1, $\mathrm{n}=$ 295)

$\begin{array}{lll}4 . & \text { I will use people to get what I want } & .72\end{array}$

45. I often find myself thinking that I am more important than others $\quad .71$

18. I find most people are weak and not worth bothering with 
38. I can often find myself viewing others as nothing more than 'objects' $\quad .60$

$\begin{array}{ll}\text { 1. I am only interested in myself } & .59\end{array}$

44. If I do something wrong I will feel bad about it $\quad .56$

16. I am not that bothered about others $\quad .56$

9. I have been described as a cruel person who does not worry about hurting $\quad .46$ others

14. I regularly view others as lazy $\quad .45$

31. If I am caught out on a lie I can quickly think of a way out

F4: Lack of sensitivity to emotion $(\alpha=.80$; Sum of squared loadings = 5.25; Mean 18.4; SD 5.8, $\mathrm{n}=$ 393; Prisoner mean 20.8, SD 6.11, $\mathrm{n}=$ 99; Student mean 17.6, SD 5.5, $\mathrm{n}=295$ )

51. Others would describe me as a very intense person who had difficulty $\quad-.54$ getting on with others.

11. Others would describe me as an irritable person with problems in -.53 controlling my temper.

34. I regularly view others as irritating -.51

32. I often experience strong positive emotion, such as happiness and joy. $\quad-.51$

28. The world is a threatening place; you have to 'watch your back'.

13. I see a lot of hostility around me.

50. I often find people behave aggressively or in a hostile manner towards $\quad-.46$ me.

39. I am an aggressive person in a number of situations. 
Table 6.

Correlations, means and reliabilities across psychopathy measures for student and forensic psychiatric sample.

\begin{tabular}{|c|c|c|c|c|c|c|c|c|c|}
\hline \multicolumn{10}{|c|}{ Student Sample $(\mathrm{n}=50)$} \\
\hline & $\begin{array}{l}\text { PAPA-II } \\
\text { Total } \\
\begin{array}{l}\alpha=.88 \\
M=60.6 / S D \\
=14.6\end{array}\end{array}$ & $\begin{array}{l}\text { PAPA-II F1 } \\
\begin{array}{l}\text { Dissocial } \\
\text { tendencies }\end{array} \\
\alpha=.78 \\
M=15.7 / \mathrm{SD} \\
=5.5\end{array}$ & $\begin{array}{l}\text { PAPA-II F2 } \\
\text { Emotional } \\
\text { detachment } \\
\alpha=.62 \\
\text { M=9.1/SD = } \\
3.2\end{array}$ & $\begin{array}{l}\text { PAPA=II F3 } \\
\text { Disregard } \\
\text { for others } \\
\begin{array}{l}\alpha=.83 \\
\mathrm{M}=20.9 / \mathrm{SD} \\
=6.1\end{array}\end{array}$ & $\begin{array}{l}\text { PAPA-II F4 } \\
\text { Lack of } \\
\text { sensitivity to } \\
\text { emotion } \\
\alpha=.71 \\
M=14.8 / S D= \\
4.6\end{array}$ & $\begin{array}{l}\text { PCL-SV } \\
\text { Total } \\
\\
\alpha=.76 \\
\text { M=2.4/SD } \\
=2.7\end{array}$ & $\begin{array}{l}\text { PCL-SV F1 } \\
\text { Interpersonal } \\
\text { style } \\
\alpha=.83 \\
M=1.1 / S D= \\
2.0\end{array}$ & $\begin{array}{l}\text { PCL-SV F2 } \\
\text { Criminal } \\
\text { history/lifestyle } \\
\alpha=.51 \\
\mathrm{M}=1.2 / \mathrm{SD}=1.3\end{array}$ & $\begin{array}{l}\text { ACL } \\
\text { Total } \\
\\
\alpha=.90 \\
M=14 . \\
3 / S D= \\
11.6\end{array}$ \\
\hline $\begin{array}{l}\text { PAPA-II } \\
\text { Total } \\
\end{array}$ & - & $.80 * * *$ & $.57 * * *$ & $.76^{* * *}$ & $.81 * * *$ & $.68 * * *$ & $.61 * * *$ & $.46^{* * *}$ & $.70 * * *$ \\
\hline $\begin{array}{l}\text { PAPA-II } \\
\text { F1 }\end{array}$ & & - & $.27 *$ & $.44 * * *$ & $.58 * * *$ & $.65 * * *$ & $.44 * * *$ & $.65 * * *$ & $.64 * * *$ \\
\hline $\begin{array}{l}\text { PAPA-II } \\
\text { F2 }\end{array}$ & & & - & .23 & $.49 * * *$ & .20 & .21 & .10 & $.27^{\mathrm{a}}$ \\
\hline $\begin{array}{l}\text { PAPA-II } \\
\text { F3 }\end{array}$ & & & & - & $.41 * *$ & $.54 * * *$ & $.57 * * *$ & .23 & $.56^{* * *}$ \\
\hline $\begin{array}{l}\text { PAPA-II } \\
\text { F4 }\end{array}$ & & & & & - & $.53 * * *$ & $.50 * * *$ & $.32 *$ & $.53 * * *$ \\
\hline
\end{tabular}

Table 6 continues 


\begin{tabular}{|c|c|c|c|c|c|c|c|c|c|}
\hline \multicolumn{10}{|c|}{ Psychiatric Patients $(n=40)$} \\
\hline & $\begin{array}{l}\text { PAPA-II } \\
\text { Total } \\
\\
\alpha=.87 \\
M=64.4 / S D \\
=16.1\end{array}$ & $\begin{array}{l}\text { PAPA-II F1 } \\
\text { Dissocial } \\
\text { tendencies } \\
\alpha=.74 \\
M=17.4 / \mathrm{SD} \\
=5.9\end{array}$ & $\begin{array}{l}\text { PAPA-II F2 } \\
\begin{array}{l}\text { Emotional } \\
\text { detachment }\end{array} \\
\begin{array}{l}\alpha=.69 \\
\mathrm{M}=9.6 / \mathrm{SD}= \\
3.4\end{array}\end{array}$ & $\begin{array}{l}\text { PAPA-II F3 } \\
\text { Disregard } \\
\text { for others } \\
\begin{array}{l}\alpha=.76 \\
M=20.3 / \mathrm{SD} \\
=6.6\end{array}\end{array}$ & $\begin{array}{l}\text { PAPA-II F4 } \\
\text { Lack of } \\
\text { sensitivity to } \\
\text { emotion } \\
\alpha=.69 \\
M=17.1 / \mathrm{SD}= \\
4.9\end{array}$ & 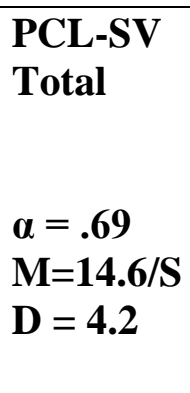 & $\begin{array}{l}\text { PCL-SV F1 } \\
\text { Interpersona } \\
\text { I style } \\
\alpha=.63 \\
M=6.3 / \mathrm{SD}= \\
2.7\end{array}$ & $\begin{array}{l}\text { PCL-SV F2 } \\
\text { Criminal } \\
\text { history/lifestyle } \\
\alpha=.64 \\
\mathrm{M}=8.3 / \mathrm{SD}=2.7\end{array}$ & $\begin{array}{l}\text { ACL } \\
\text { Total } \\
\alpha=.92 \\
M=82 . \\
1 / S D= \\
24.6\end{array}$ \\
\hline $\begin{array}{l}\text { PAPA-II } \\
\text { Total }\end{array}$ & - & $.78^{* * *}$ & $.76^{* * * *}$ & $.77 * * *$ & $.77 * *$ & $.44 * *$ & $.36^{*}$ & $.34^{*}$ & $.45^{* *}$ \\
\hline $\begin{array}{l}\text { PAPA-II } \\
\text { F1 }\end{array}$ & & - & $.56^{* * * *}$ & $.33^{*}$ & $.51 * * *$ & $.35 *$ & .15 & $.41 * *$ & $.35^{*}$ \\
\hline $\begin{array}{l}\text { PAPA-II } \\
\text { F2 }\end{array}$ & & & - & $.49 * * *$ & $.46^{* *}$ & $.40 * *$ & $.34 *$ & $.30^{\mathrm{a}}$ & $.40 * *$ \\
\hline $\begin{array}{l}\text { PAPA-II } \\
\text { F3 }\end{array}$ & & & & - & $.43 * * *$ & .27 & .23 & .20 & $.37 *$ \\
\hline $\begin{array}{l}\text { PAPA-II } \\
\text { F4 }\end{array}$ & & & & & - & $.38 * *$ & $.44 * *$ & .16 & $.28^{b}$ \\
\hline
\end{tabular}

